\title{
A novel form of ataxia oculomotor apraxia characterized by oxidative stress and apoptosis resistance
}

\author{
N Gueven ${ }^{1}$, OJ Becherel ${ }^{1}$, O Howe ${ }^{1,2}$, P Chen ${ }^{1}$, J-F Haince ${ }^{3}$, M-E Ouellet ${ }^{3}$, GG Poirier ${ }^{3}$, N Waterhouse ${ }^{4}$, M Fußer $^{5}$, B Epe $^{5}$,

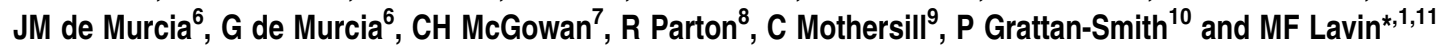

\begin{abstract}
Several different autosomal recessive genetic disorders characterized by ataxia with oculomotor apraxia (AOA) have been identified with the unifying feature of defective DNA damage recognition and/or repair. We describe here the characterization of a novel form of AOA showing increased sensitivity to agents that cause single-strand breaks (SSBs) in DNA but having no gross defect in the repair of these breaks. Evidence for the presence of residual SSBs in DNA was provided by dramatically increased levels of poly (ADP-ribose)polymerase (PARP-1) auto-poly (ADP-ribosyl)ation, the detection of increased levels of reactive oxygen/nitrogen species (ROS/RNS) and oxidative damage to DNA in the patient cells. There was also evidence for oxidative damage to proteins and lipids. Although these cells were hypersensitive to DNA damaging agents, the mode of death was not by apoptosis. These cells were also resistant to TRAIL-induced death. Consistent with these observations, failure to observe a decrease in mitochondrial membrane potential, reduced cytochrome $c$ release and defective apoptosis-inducing factor translocation to the nucleus was observed. Apoptosis resistance and PARP-1 hyperactivation were overcome by incubating the patient's cells with antioxidants. These results provide evidence for a novel form of AOA characterized by sensitivity to DNA damaging agents, oxidative stress, PARP-1 hyperactivation but resistance to apoptosis.
\end{abstract}

Cell Death and Differentiation (2007) 14, 1149-1161. doi:10.1038/sj.cdd.4402116; published online 9 March 2007

Hereditary ataxias represent a heterogenous group of rare disorders characterized by cerebellar ataxia that is usually progressive. Aicardi et al. ${ }^{1}$ described 14 patients with a syndrome ataxia oculomotor apraxia (AOA). The clinical phenotype of $A O A$ is observed in a number of different genetic disorders, including ataxia-telangiectasia (A-T), A-Tlike disorder (A-TLD), AOA type 1 (AOA1) and AOA type 2 (AOA2). A-T is a distinctive clinical syndrome ${ }^{2}$ caused by mutations in the ataxia-telangiectasia mutated (ATM) gene ${ }^{3}$ and characterized by early-onset-ataxia with rapid progression, extrapyramidal signs, peripheral neuropathy, recurrent infections, malignancies and telangiectasis. ${ }^{2,4}$ A-TLD closely overlaps with A-T in its clinical and cellular phenotype, onset is in the first decade of life but disease progression is slower than for A-T. ${ }^{5}$ The defective gene product in A-TLD, Mre11, forms a complex with Nbs1 (mutated in Nijmegen Breakage Syndrome) and Rad50 to act as a sensor of DNA-doublestrand breaks. ${ }^{6,7}$ Mre11 or Nbs1 mutations decrease ATM activation and phosphorylation of downstream substrates. ${ }^{8}$
Onset of AOA1 is in the first decade. Initially, ataxia and/or chorea are predominant symptoms but by the early adult years there is a severe neuropathy. ${ }^{9}$ Hypoalbuminemia and hypercholesterolemia also develop with increasing disease duration. AOA1 patients have mutations in the APTX gene, which maps to chromosome 9p13.3. Aprataxin, the APTX gene product, contains three putative domains, a forkhead associated domain for interaction with phosphorylated proteins, a histidine triad (HIT) domain that has AMP-lysine hydrolase and nucleotide hydrolytic activities and a C-terminal zinc-finger domain implicated in DNA repair. ${ }^{10-13}$ Recent data reveal that aprataxin plays a functional role in resolving abortive DNA ligation intermediates. ${ }^{14}$ Onset of AOA2 is usually in the second decade, disease progression is less aggressive than in AOA1 but neuropathy and extrapyramidal movements are also seen. ${ }^{15}$ Moderate elevation of $\alpha$-fetoprotein is also a biological marker in some cases. The gene defective in AOA2, SETX, codes for senataxin, a 2677 amino-acids protein containing a classical superfamily 1

\footnotetext{
${ }^{1}$ Department of Cancer and Cell Biology, Queensland Institute of Medical Research, Brisbane, Queensland, Australia; ${ }^{2}$ Radiation and Environmental Science Centre, Focas Institute, Dublin Institute of Technology, Dublin, Ireland; ${ }^{3}$ Departement de Biologie Medicale, Faculty of Medicine, Health and Environment Unit, Laval University Hospital Research Center, CHUQ, Laval University, Quebec, Canada; ${ }^{4}$ Cancer Immunology Program, Peter MacCallum Cancer Centre, Melbourne, Victoria, Australia; ${ }^{5}$ Pharmakologie und Toxikologie, Institute of Pharmacy, University of Mainz, Mainz, Germany; ${ }^{6}$ Département Intégrité du Génome de l'UMR 7175, CNRS, Laboratoire Conventionné avec le Commissariat à l'Energie Atomique Ecole Supérieure de Biotechnologie de Strasbourg, Illkirch-Cedex, France; ${ }^{7}$ Department of Molecular Biology, The Scripps Research Institute, La Jolla, CA, USA; ${ }^{8}$ Centre for Microscopy and Microanalysis, The University of Queensland, Brisbane, Queensland, Australia; ${ }^{9}$ Department of Medical Physics, McMasters University, Hamilton, Ontario, Canada; ${ }^{10}$ Department of Neurology, Sydney Children's Hospital, New South Wales, Australia and ${ }^{11}$ Department of Surgery, University of Queensland, Central Clinical School, Brisbane, Queensland, Australia

${ }^{*}$ Corresponding author: MF Lavin, Queensland Institute of Medical Research, Post Office Royal Brisbane Hospital, Queensland 4029, Australia.

Tel: 61-7-33620341; Fax: 61-7-33620106; E-mail: martinL@ qimr.edu.au

Keywords: ataxia oculomotor apraxia; agent sensitivity; apoptosis; PARP cleavage and hyperactivation; cytochrome $C$; mitochondrial transmembrane potential Abbreviations: AOA, ataxia oculomotor apraxia; A-T, ataxia-telangiectasia; A-TLD, A-T like disorder; ATM, ataxia-telangiectasia mutated; PARP-1, poly(ADPribose)polymerase 1

Received 08.6.06; revised 19.1.07; accepted 29.1.07; Edited by SH Kaufmann; published online 09.3.07
} 
seven-motif-helicase-domain at its C-terminus and is homologous to yeast proteins implicated in DNA repair. ${ }^{16}$ It appears likely that all four syndromes with an overlapping clinical phenotype of AOA have some form of DNA processing defect. $^{7,12,14,16,17}$ Thus, it is likely that this defect in DNA repair/processing contributes to the neurodegeneration common to these syndromes. We have recently described a defective $\mathrm{p} 53$ response in cells from a patient with an A-T-like clinical phenotype but with normal ATM activation and downstream signalling. ${ }^{18}$ We report here evidence for agent sensitivity, oxidative stress, poly (ADP-ribose)polymerase (PARP-1) hyperactivation and a mode of cell death in patient's cells not involving apoptosis.

\section{Results}

Sensitivity to DNA damaging agents. As this patient overlaps in phenotype with A-T, A-TLD and AOA1, it was possible that his cells (ATL2ABR) might also be sensitive to DNA damaging agents. The results in Figure 1a demonstrate that ATL2ABR cells are significantly more sensitive to $\mathrm{H}_{2} \mathrm{O}_{2}$ than control cells, whereas by comparison, A-T cells (AT1ABR) show a normal response. On the other hand, although A-T cells display extreme sensitivity to ionizing radiation, ATL2ABR cells are intermediate in their response. These cells also showed increased sensitivity to mitomycin $C$ (MMC), etoposide and methylnitronitrosoguanidine (MNNG) but exhibited a normal response to camptothecin (CPT) and methylmethanesulfonate (MMS). This increased sensitivity to MMC is also apparent when DNA damage-induced chromosome aberrations (ICAs) are determined (Figure 1b). ATL2ABR cells show more than double the number of aberrations compared with control cells in response to treatment with MMC. This is also the case after exposure of cells to ionizing radiation. The number of ICAs is intermediate between those of control and A-T cells (Figure 1c). It is also of interest that cells from both parents show elevated levels of ICAs compared with control cells. Elevated ICAs were also found in one of the patient's siblings.

DNA single-strand break repair in ATL2ABR cells. As ATL2ABR cells showed increased sensitivity to agents that cause single-strand breaks (SSBs) in DNA, we determined whether ATL2ABR cells were deficient in DNA SSB repair using alkaline elution assay. When control and ATL2ABR cells were exposed to different doses of $\mathrm{H}_{2} \mathrm{O}_{2}$, a timedependent reduction in DNA breaks was observed, which was comparable in both cell types (Figure 2).

Figure 1 Sensitivity to DNA damaging agents. (a) Cell survival of lymphoblastoid control (C3ABR), A-T (AT1ABR, GM03189), AOA1 (939), AOA2 (654) and patient (ALT2ABR) cell lines in response to genotoxic agents (IR: ionizing radiation; $\mathrm{CPT}$ : camptothecin; $\mathrm{H}_{2} \mathrm{O}_{2}$ : hydrogen peroxide; MMC: mitomycin $\mathrm{C}$; MMS: methylmethanesulfonate; MNNG: methylnitonitroso-guanidine and Etoposide). (b) DNA damage-ICA in response to MMC. (c) ICA in response to ionizing radiation. After treatment with the genotoxic agent, 50 metaphases were scored for each cell line for chromosome aberrations (sb: chromatid breaks; cb: chromosome breaks; Int: interchanges)
PARP-1 hyperactivation in ATL2ABR cells. We also measured activity of PARP-1 as a readout for repair of DNA SSBs. Surprisingly, PARP-1 was already hyperactivated, as
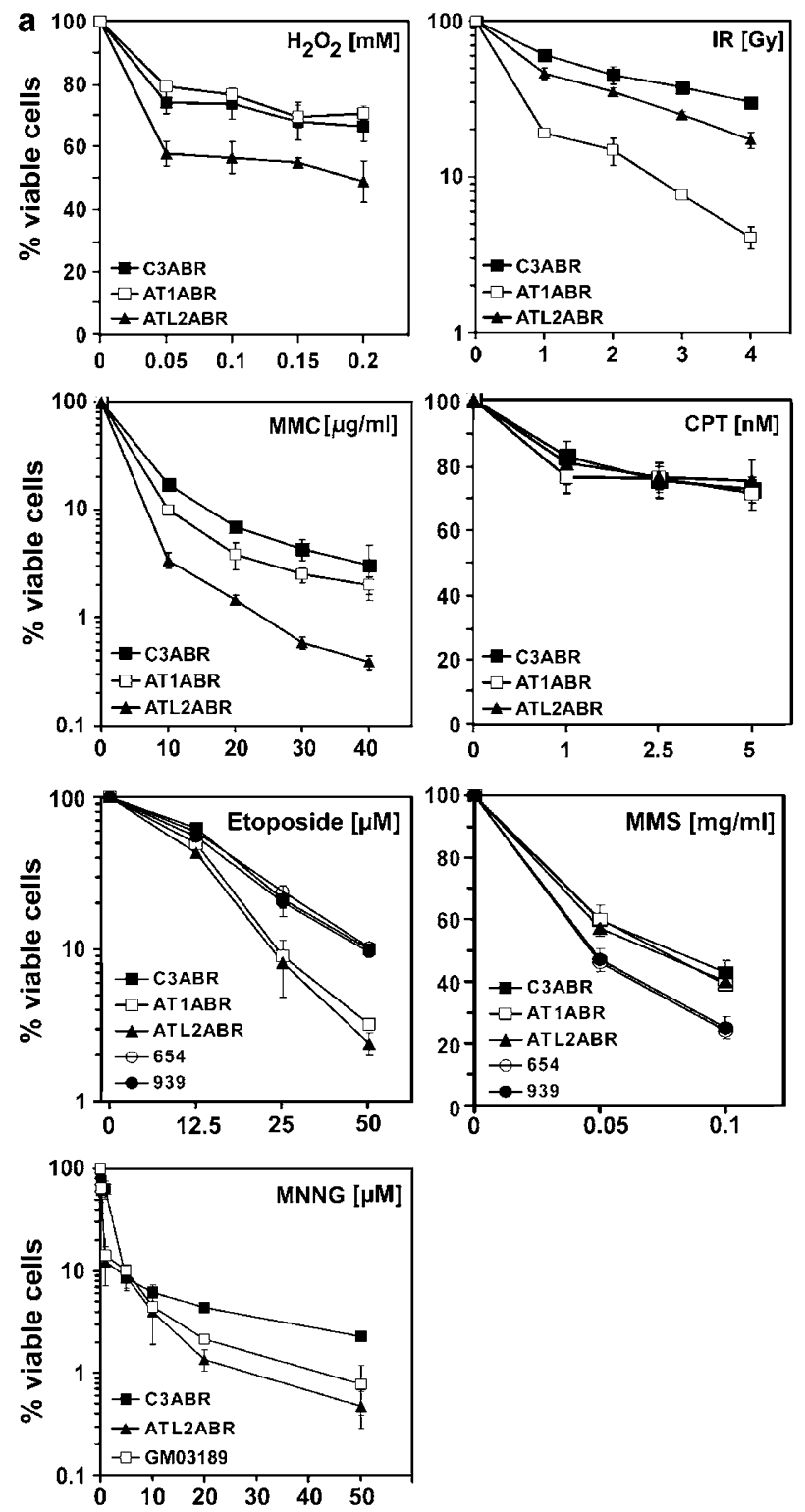

b MMC-induced chromosome aberrations

\begin{tabular}{|l|cc|c|c|}
\hline \multicolumn{1}{|c|}{ Cell Line } & SB & CB & Int & ICA \\
C3ABR (control) & 24 & 0 & 4 & 0.56 \\
\hline ATL2ABR & 56 & 4 & 4 & 1.28 \\
\hline
\end{tabular}

c

Radiation-induced chromosome aberrations

\begin{tabular}{|l|c|c|c|c|}
\hline \multicolumn{1}{|c|}{ Cell Line } & SB & CB & Int & ICA \\
\hline C3ABR (control) & 53 & 0 & 1 & 1.08 \\
\hline AT1ABR (A-T) & 160 & 0 & 0 & 3.20 \\
\hline Father & 100 & 2 & 1 & 2.06 \\
\hline Mother & 113 & 0 & 2 & 2.30 \\
\hline ATL2ABR & 133 & 0 & 1 & 2.68 \\
\hline Brother 1 & 69 & 0 & 0 & 1.39 \\
\hline Brother 2 & 95 & 1 & 5 & 2.02 \\
\hline
\end{tabular}




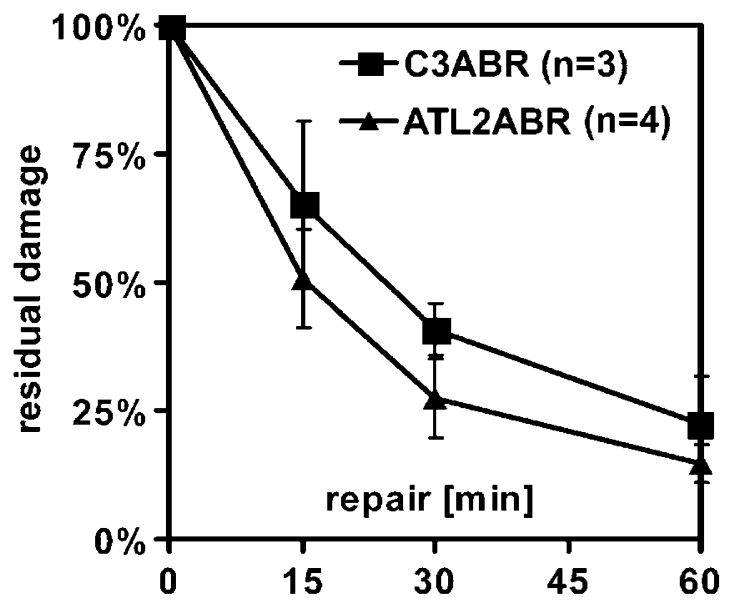

Figure 2 DNA SSB repair in ATL2ABR. In vivo repair of ROS-induced SSBs induced by $\mathrm{H}_{2} \mathrm{O}_{2}$. Residual SSBs were quantified by the alkaline elution method at different times after treatment of lymphoblastoid control (C3ABR) and patient's (ATL2ABR) cells with $20 \mu \mathrm{M} \mathrm{H}_{2} \mathrm{O}_{2}$. Error bars represent S.D. of an average of three (C3ABR) and four (ATL2ABR) independent experiments

determined by PAR levels in untreated ATL2ABR cells (Figure 3a). This hyperactivation does not appear to be explained by increased basal levels of DNA SSBs, as there was $<0.05$ breaks per $10^{6}$ base pairs in control and ATL2ABR cells (results not shown). However, break numbers below this level of detection could still be sufficient to activate PARP1. In response to $\mathrm{H}_{2} \mathrm{O}_{2}$ exposure, a time-dependent decrease in PARP-1 activity was observed in ATL2ABR cells indicative of repair of strand breaks. No hyperactivation was observed in an untreated control cell line but $\mathrm{H}_{2} \mathrm{O}_{2}$ exposure increased PARP-1 activity transiently, as has been reported elsewhere. ${ }^{19}$

A comparison of basal PAR levels in different lymphoblastoid cells from either control (C2ABR, C3ABR, C4ABR, C5ABR), patient (ATL2ABR), AOA1 (L990, L991, L938), AOA2 (SETX-2RM), A-T (AT5ABR) or Friedreich ataxia (FRDA1) demonstrated that PARP-1 activity was significantly elevated only in the patient's cells (Figure $3 b$ ). In order to determine whether these increased levels of PAR were due to increased levels of PARP-1 activity, we treated cells with 3-aminobenzamide (3-AB) an inhibitor of PARP activity. This inhibitor completely abolished $\mathrm{H}_{2} \mathrm{O}_{2}$-induced PARP-1 activity in both ATL2ABR and control cells. The high basal level of PAR in ATL2ABR cells was also abolished by 3-AB (data not shown), suggesting that these elevated levels are due to hyperactive PARP-1 (Figure 3c). The hyperactivation of PARP-1 might be explained by decreased activity of poly(ADP)-glycohydrolase (PARG), which removes PAR from proteins. ${ }^{20}$ An autoradiographic approach with impregnated $\left[{ }^{32} \mathrm{P}\right]$-labelled automodified PARP-1 as substrate failed to reveal any difference in PARG activity under basal or DNA damage-induced conditions in control and ATL2ABR cells (Figure $3 d$ ). This is further substantiated by an in vitro assay for PARG activity in the two cell lines (Figure 3 e).

ATL2ABR cells were generated from a patient displaying a neurodegenerative phenotype, characterized by cerebellar atrophy, ataxic gait and oculomotor apraxia. Previous data have demonstrated a link between activation of PARP-1 and neurodegeneration, ${ }^{21}$ which might also be responsible for the phenotype observed here. Thus, we employed specific inhibitors of PARP-1 to determine their effect on the cellular phenotype of ATL2ABR cells. Exposure of control cells to increasing concentrations of the PARP inhibitors PJ-34 (Figure 3f) or AG-1436 (Figure 3g) had only minimal effects on cell survival, whereas exposure of ATL2ABR cells to both inhibitors resulted in a significant loss in viability. These data suggest that the hyperactivation of PARP-1 represents a, compensatory mechanism in response to physiological stress in these cells. To determine whether ATL2ABR cells are under stress, we measured oxidative damage to protein (nitrotyrosine), DNA (8-oxo-dG) and lipids (4HNE). The results in Figure 4 demonstrate that immunoreactivity for all three markers was markedly elevated in untreated primary patient fibroblasts (PSF) compared with NFF, indicative of increased levels of oxidative stress in these cells.

Mode of cell death in ATL2ABR in response to DNA damage. The presence of chronic oxidative stress in the cells from the patient could contribute to the failure to observe caspase activation and induction of apoptosis in these cells, ${ }^{18}$ as there is evidence that nitric oxide delays the release of mitochondrial cytochrome $c$ and prevents the activation of execution caspases. ${ }^{22}$ In order to investigate this further, we quantified the apoptotic response using FACS analysis of Annexin $\mathrm{V}$ and propidium iodide (PI) staining in response to $\mathrm{H}_{2} \mathrm{O}_{2}$ (Figure 5a). Twenty-four hours after treatment with $\mathrm{H}_{2} \mathrm{O}_{2}$ a substantial portion of the control cells showed high Annexin $\mathrm{V}$ staining combined with low PI staining $(11.81 \%$ treated versus $2.28 \%$ untreated; lower right quadrant), indicative of apoptosis. At the same time, this $\mathrm{H}_{2} \mathrm{O}_{2}$-induced increase was only marginal in ATL2ABR cells $(3.47 \%$ treated versus $2.54 \%$ untreated). On the contrary, the fraction of cells with high PI staining and low Annexin $V$ signal (upper left quadrant), indicative of DNA damage-induced necrosis, was higher in ATL2ABR (16.6\%) compared with C3ABR cells $(1.47 \%)$. To determine whether the apoptotic defect was also evident in the other members of the family similar experiment were carried out as described above. The results in Figure $5 \mathrm{~b}$ failed to detect increased sensitivity (loss of cell viability) in cells from relatives of the patient. However, cells from the patient's mother and two siblings also showed resistance to $\mathrm{H}_{2} \mathrm{O}_{2}$-induced apoptosis, whereas the father's cells displayed levels of apoptosis comparable to control cells (C2ABR) (Figure 5c). When cells were exposed to either a DNA damaging agent (Etoposide: E) or a non-DNA damaging agents (Trail: T) extensive PARP-1 cleavage was observed in control cells, $8 \mathrm{~h}$ post-treatment, but no cleavage of PARP-1 occurred in ATL2ABR cells, demonstrating a more general resistance to apoptosis in these cells (Figure $5 \mathrm{~d}$ ).

No change in mitochondrial membrane potential in patient's cells after DNA damage. DNA damage-induced apoptosis proceeds by a mechanism involving mitochondrial outer membrane permeabilization (MOMP). ${ }^{23}$ The mechanism of MOMP is complex and involves dissipation of the inner mitochondrial transmembrane potential $(\Delta \Psi \mathrm{m})$ and is promoted by proapoptotic Bcl2-family members. ${ }^{23}$ To characterize the form of cell death, we determined whether 


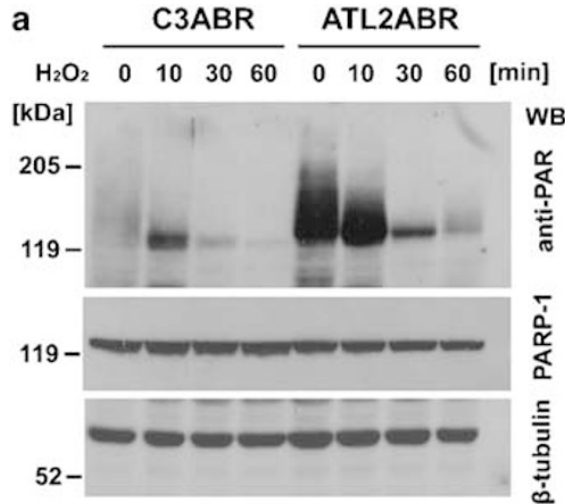

C
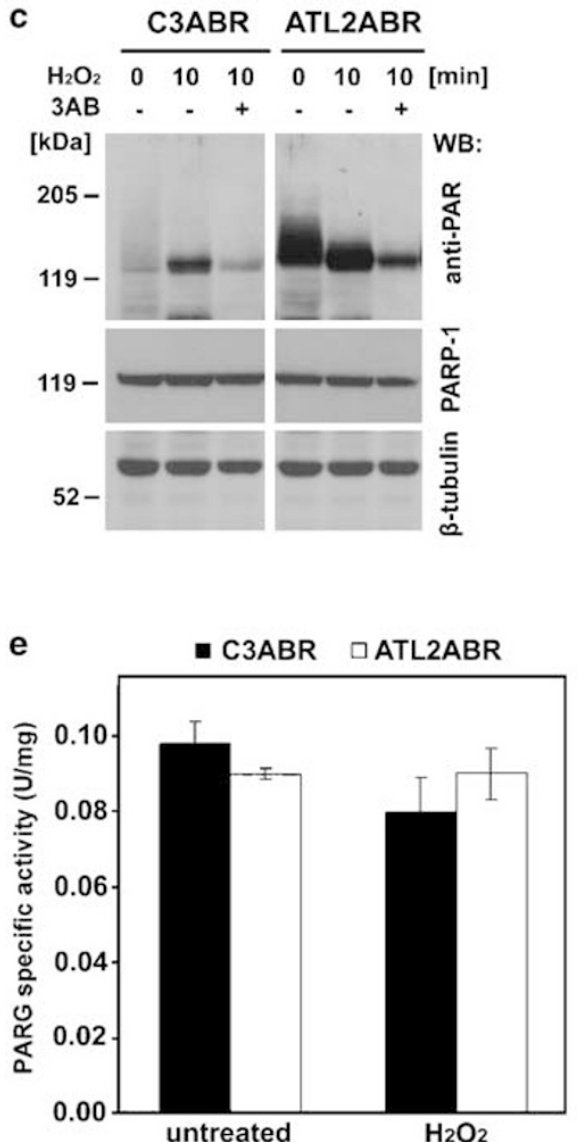

b

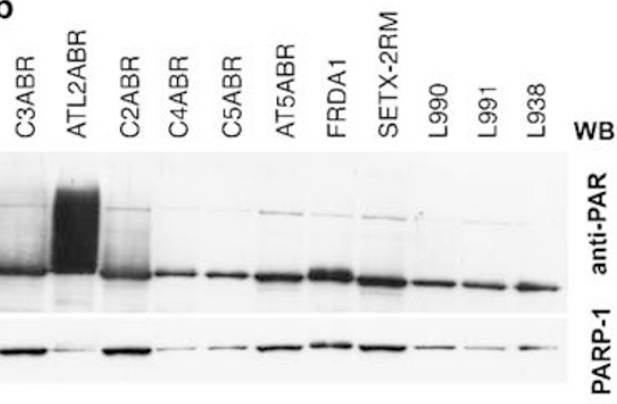

d
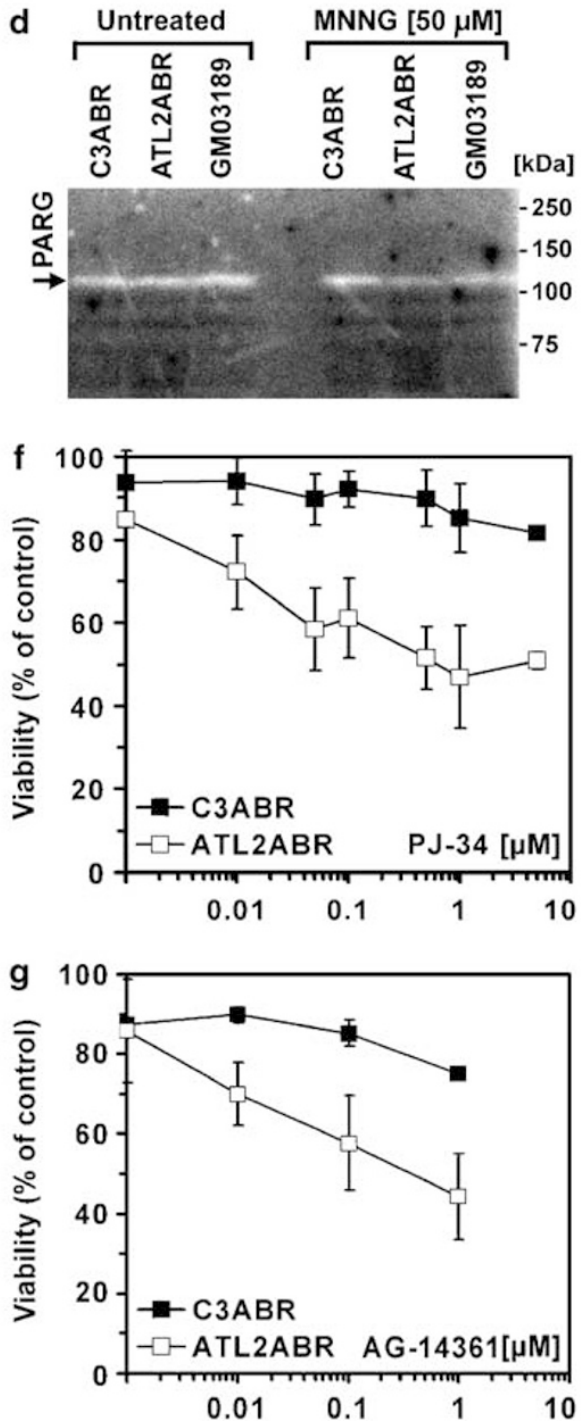

Figure 3 Activity of PARP and PARG in ATL2ABR. (a) Basal and DNA damage-induced poly-ADP-ribose (PAR) levels. Control (C3ABR) and patient (ATL2ABR) lymphoblastoid cells were exposed to $500 \mu \mathrm{M} \mathrm{H} 2 \mathrm{O} 2$ for time intervals as indicated and PAR levels detected by SDS-PAGE and Western blotting. Detection of PARP-1 and $\beta$ tubulin served as loading control. (b) Comparison of PAR levels in different LCLs. Total cell extracts from control (C2ABR, C3ABR, C4ABR, C5ABR), patient (ATL2ABR), AOA1 (L990, L991, L938), AOA2 (SETX-2RM), A-T (AT5ABR) and Friedreich ataxia (FRDA1) cells were probed for poly-ADP-ribose (PAR) and PARP-1 levels. (c) Effect of PARP1 inhibitor, 3-amino benzamide (3AB, $1 \mathrm{mM}$ ) on DNA damage-induced PAR levels. Cells were untreated or pretreated for $4 \mathrm{~h}$ with the PARP-1 inhibitor 3-AB before treatment with $\mathrm{H} 2 \mathrm{O} 2$ for $10 \mathrm{~min}$. Subsequently, PAR levels were detected as above. (d) PARG activity was measured in control and patient's lymphoblastoid cells. Total extracts of untreated cells or exposed to $50 \mu \mathrm{M}$ MNNG for 10 min were prepared and enzymatic activity was detected by performing a zymogram. (e) Histogram displaying PARG-specific activity in control and patient cells exposed to $500 \mu \mathrm{M} \mathrm{H}_{2} \mathrm{O}_{2}$ for $10 \mathrm{~min}$. PARG activity was measured by in vitro assay and data are expressed as mean \pm S.E.M. from three independent experiments. (f) Relative sensitivity of control and patient's cells to the high affinity PARP-1 inhibitor PJ-34. Both cell lines were treated with an increasing amount of PJ-34 and viability was determined as described in the Materials and methods. Each point represents the average of triplicate experiments \pm S.E.M. (g) Relative sensitivity of control and patient's cells to the high affinity PARP-1 inhibitor AG-14361 
the mitochondrial membrane potential $(\Delta \Psi \mathrm{m})$ was altered in PSFs in response to DNA damage. Changes to the membrane potential were visualized by fluorescence emission of a cyanine dye (JC-1). Treatment of NFF with $\mathrm{H}_{2} \mathrm{O}_{2}$ led to a loss of the aggregated (red-fluorescent) form of $\mathrm{JC}-1$ within $30 \mathrm{~min}$, indicative of a loss of mitochondrial membrane potential (Figure 6a). No such loss was observed from the mitochondria in PSF even after $60 \mathrm{~min}$ posttreatment. The use of electron microscopy to examine the mitochondrial ultrastructure failed to reveal any difference between the two cell types (data not shown).

An early event in response to MOMP is the release of cytochrome $c$ and other proapoptotic factors as part of the apoptotic cascade. Release of cytochrome $c$ into the cytosol gives rise to a complex with procaspase 9 and APAF-1 that promotes caspase activation and downstream events in apoptosis. ${ }^{23}$ In control cells (C3ABR) undergoing etoposideinduced apoptosis, cytochrome $c$ release was evident by $4 \mathrm{~h}$ post-treatment and continued to increase up to $8 \mathrm{~h}$ (Figure 6b). A low level of release into the cytoplasm was also evident by $4 \mathrm{~h}$ in ATL2ABR cells but this showed little further increase compared with controls up to $8 \mathrm{~h}$ post-treatment. As an additional measure of mitochondrial integrity in response to $\mathrm{H}_{2} \mathrm{O}_{2}$, we determined the release of apoptosis-inducing factor (AIF) from the mitochondria and its translocation to the nucleus. In response to $\mathrm{H}_{2} \mathrm{O}_{2}$, a time-dependent nuclear accumulation of AIF was observed in control lymphoblastoid cells but only a very weak response was evident in ATL2ABR cells (Figure $6 \mathrm{c}$ ). This was confirmed using fibroblasts, which showed that AIF was translocated from a cytoplasmic localization into the nucleus of NFF within 30 min of treatment with $\mathrm{H}_{2} \mathrm{O}_{2}$ (Figure $6 \mathrm{~d}$ ). This relocalization did not occur in PSF up to $2 \mathrm{~h}$ post-treatment. Overall, these results suggest that the patient's mitochondria are refractory to changes in membrane permeability in response to DNA damage that is a prerequisite for apoptotic killing. In order to investigate mitochondrial function further, we also measured the levels of ATP in these cells. The result in Figure $6 \mathrm{e}$ demonstrate a reduction in ATP levels in ATL2ABR cells to approximately $50 \%$ of that in controls.

Reversal of the oxidative phenotype in patient's cells using antioxidants. A common approach for quantitative assessment of cellular oxidative stress is the use of redox sensitive dyes. The results in Figure 4 demonstrate increased oxidative damage in primary PSFs. To confirm that oxidative stress is not restricted to this cell type but is also characteristic of the patient's lymphoblastoid cell line (LCL) ATL2ABR, 5-(and 6-)chloromethyl-2', 7'-dichlorodihydrofluorescein diacetate, acetyl ester (CM- $\mathrm{H}_{2}$-DCFDA) staining was used to probe the levels of oxidative/nitrosative reactive species (ROS/RNS) in these cells. Flow cytometric analysis clearly showed a right-shifted profile for ATL2ABR cells (green curve) compared with control cells (C2ABR; black curve) towards increased fluorescence, indicative of higher levels of ROS/RNS in the patient's cells (Figure 7a). To assess the effectiveness of antioxidants in reducing ROS/RNS levels, ATL2ABR cells were pretreated for 1 or 9 days with the antioxidant $N$-acetyl-cysteine (NAC; $500 \mu \mathrm{M}$; Figure 7b) or the iron chelator Desferal (200 nM;
Figure 7c). A significant reduction in ROS/RNS was observed after 1 day treatment with both compounds indicated by lower proportion of cells in the high fluorescent region. Treatment with antioxidants for 9 days did not reduce ROS/RNS levels further. Although NAC reduced the levels of ROS/RNS within 1 day, it failed to eliminate the products of oxidative stress, monitored by $4 \mathrm{HNE}$ and 3-nitro-tyrosine immunoreactivity, in the PSFs at the same time. However, incubation with NAC for 9 days significantly reduced $4 \mathrm{HNE}$ and 3-nitro-tyrosine levels (Figure 7d). Desferal reduced $4 \mathrm{HNE}$ immunoreactivity within 1day only at a high dose $(1 \mu \mathrm{M}$; Figure $7 \mathrm{~d})$.

Restoring apoptosis and normal PARP-1 activity in ATL2ABR cells using antioxidants. Lee and Shacter $(2000)^{22}$ have shown that oxidants such as $\mathrm{H}_{2} \mathrm{O}_{2}$ can manipulate cell death pathways, diverting the cell away from apoptosis at least in part by activation of PARP-1. To investigate whether there was a relationship among oxidative/nitrosative stress, PARP- 1 hyperactivation and the apoptotic defect in ATL2ABR, cells were pretreated for $1 \mathrm{~h}$ with the PARP-1 inhibitor $3-A B$ or the antioxidant isoindoline nitroxide 5-carboxy-1,1,3,3-tetramethylisoindolin-2-yloxyl $(\mathrm{CTMIO})^{24}$ before DNA damage was induced by etoposide. CTMIO is a member of a family of stable free radicals that act as radical chain terminators, oxidize metals to prevent Fenton-reaction-derived free radicals and act catalytically as superoxide dismutase mimetics. ${ }^{25}$ Although we showed that $3-A B$ treatment effectively inhibited PARP-1 activity (see Figure $3 c$ ), it did not restore etoposide-induced apoptosis in ATL2ABR cells as measured by PARP-1 cleavage (Figure 8a, lane 12). Despite the high levels of oxidative stress in the patient's cells, overnight treatment with CTMIO did not restore etoposide-induced apoptosis (Figure 8a, lane 11). In control cells neither 3-AB nor CTMIO showed any effect on etoposide-induced apoptosis (Figure 8a, lanes 5 and 6). However, when cells were incubated for 9 days with the antioxidant NAC or the iron chelator Desferal, etoposideinduced apoptosis was restored in ATL2ABR cells as determined by cleavage of PARP-1 (Figure 8b). Neither NAC nor Desferal alone caused apoptosis. The results above demonstrate that inhibition of PARP-1 failed to restore agent-induced apoptosis in ATL2ABR cells suggesting that PARP-1 hyperactivation is not upstream of apoptosis inhibition and is an independent consequence of oxidative stress. The results in Figure $8 \mathrm{c}$ reveal that both antioxidants significantly reduce PAR levels in ATL2ABR cells, supporting this contention.

\section{Discussion}

We have described here, cellular characteristics of what appears to be a novel form of AOA characterized by hypersensitivity to DNA damaging and other agents, oxidative stress and a mode of cell death not involving apoptosis. AOA represents a subgroup of autosomal recessive, spinocerebellar ataxias characterized by neurodegeneration and abnormal eye movements. ${ }^{9,26}$ At the cellular level these syndromes also feature abnormalities in DNA damage recognition and/or repair. A-T and A-TLD cells are defective 

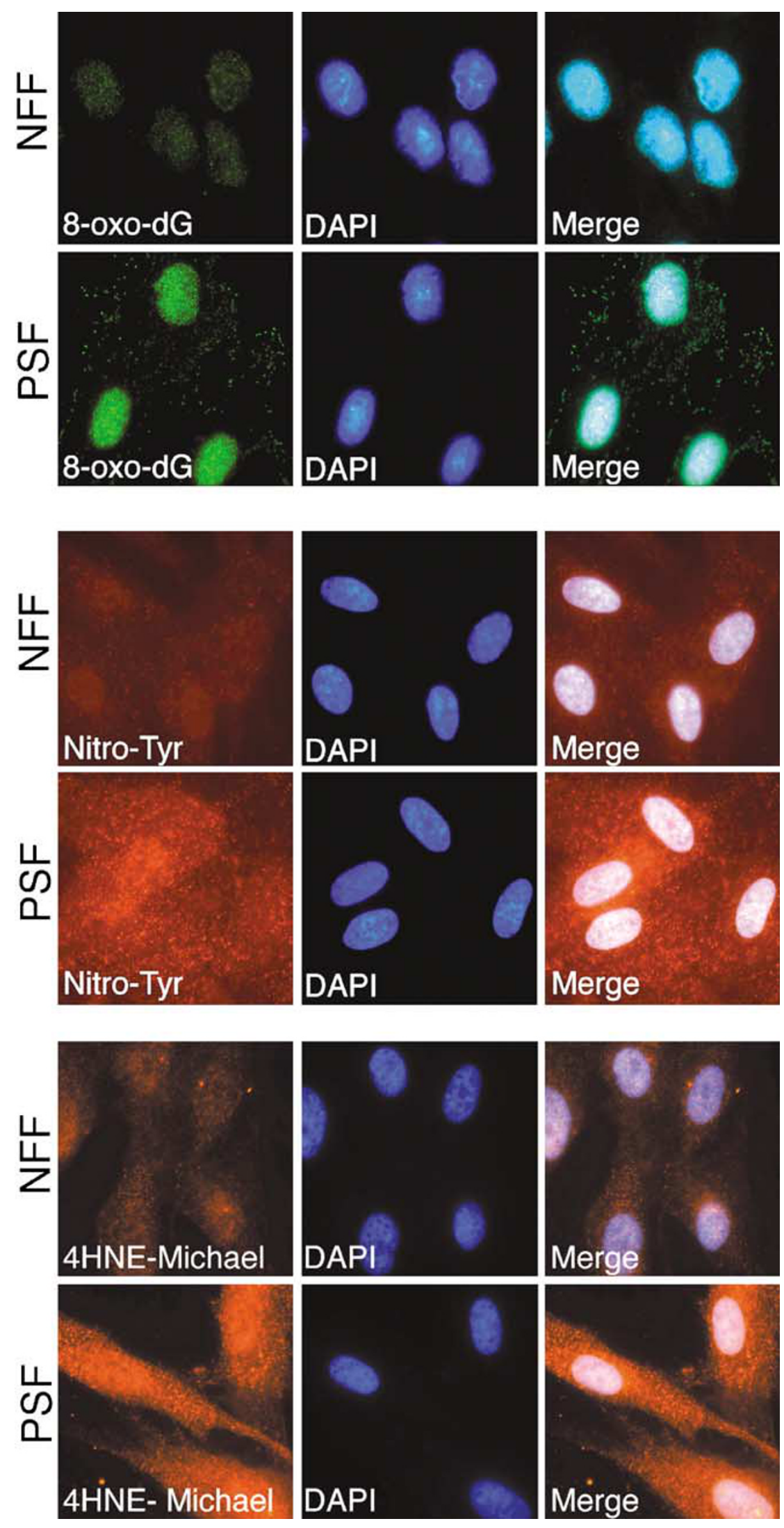
in the recognition and signalling of DNA double-strand breaks. ${ }^{7}$ AOA1 cells are defective in DNA SSB repair, ${ }^{12,27,28}$ which may be related to a failure to efficiently resolve abortive DNA ligation intermediates. ${ }^{14}$ AOA2 cells are defective in a protein (senataxin) homologous to a yeast protein involved in DNA repair and RNA processing. ${ }^{16,29}$ Given the cellular characteristics described here for the patient, together with the overlapping clinical phenotype of this patient with other AOA syndromes, it seems likely that the defective gene in this case will also be associated with some aspect of DNA damage processing and signalling to apoptosis. However, no mutations were observed in APTX, SETX or ATM in the patient's cells. We have previously provided evidence that cells from the patient have a defective p53 response to ionizing a

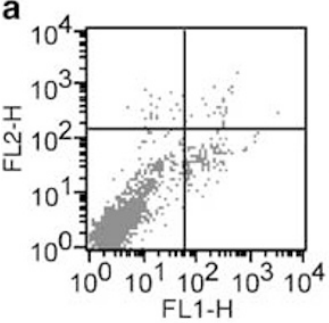

C3ABR untreated

\begin{tabular}{cr} 
Quad & $\%$ Gated \\
\hline UL & 0.47 \\
UR & 0.49 \\
LL & 96.77 \\
LR & 2.28
\end{tabular}

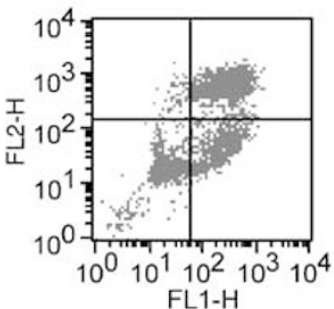

C3ABR 24h $0.5 \mathrm{mM} \mathrm{H}_{2} \mathrm{O}_{2}$

\begin{tabular}{cr} 
Quad & $\%$ Gated \\
\hline UL & 1.47 \\
UR & 62.97 \\
LL & 23.76 \\
LR & 11.81
\end{tabular}

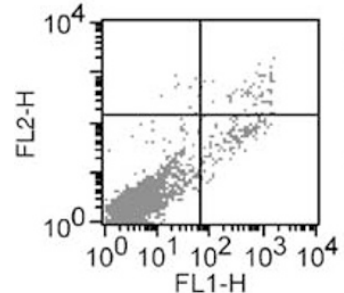

\begin{tabular}{lr}
\multicolumn{2}{l}{ ATL2ABR } \\
untreated \\
Quad $\%$ & Gated \\
\hline UL & 0.18 \\
UR & 1.29 \\
LL & 95.98 \\
LR & 2.54
\end{tabular}

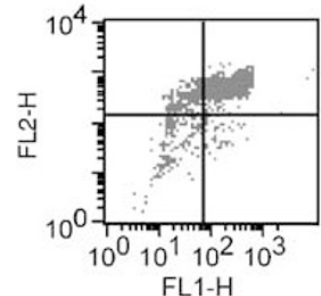

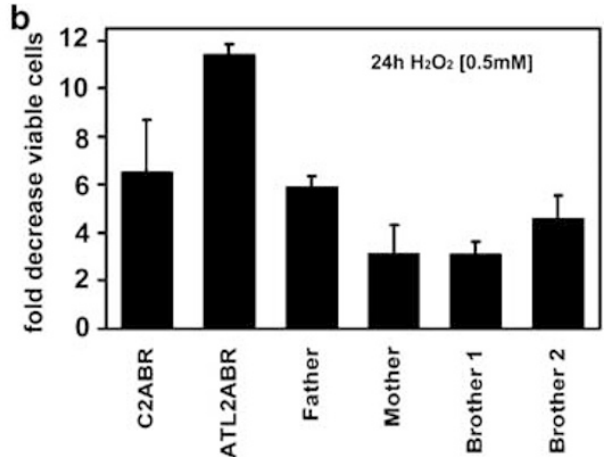
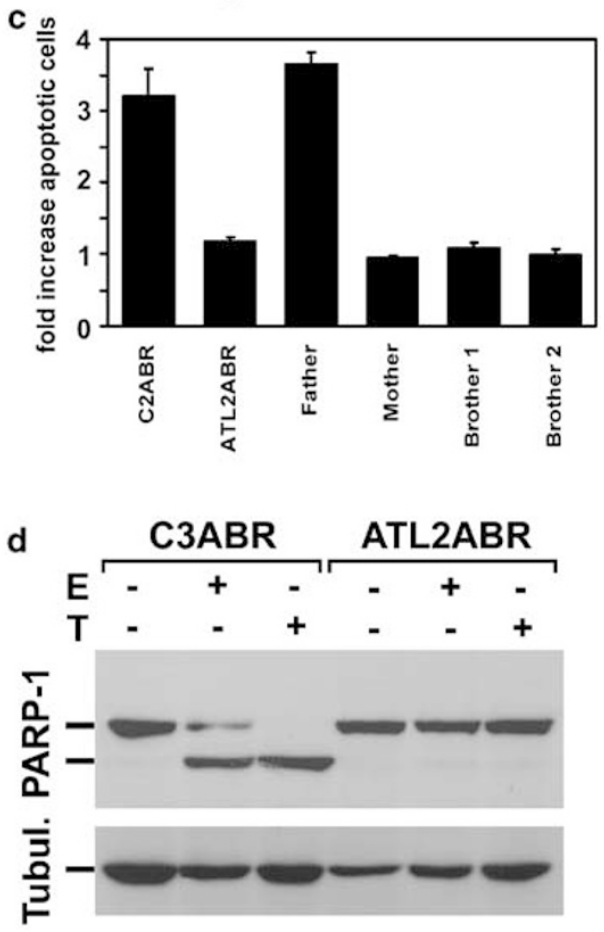

Figure 5 Characterization of agent-induced cell death. (a) FACS analysis of DNA damage-induced apoptosis. Lymphoblastoid control (C3ABR) and patient's cells (ATL2ABR) were untreated or treated with $\mathrm{H}_{2} \mathrm{O}_{2}$ for $24 \mathrm{~h}$ and analysed for phosphatidylserine exposure (Annexin $\mathrm{V}$ binding) and plasma membrane rupture (PI uptake) by FASC analysis. The fluorescence intensities of Annexin V-FITC (FL-1) and PI (FL-2) are presented as dot plots. The percentage of live cells (Annexin V-ve/PI-ve), apoptotic cells (Annexin $\mathrm{V}+\mathrm{ve} / \mathrm{PI}-\mathrm{ve}$ ) and necrotic or cells that had progressed through apoptosis to secondary necrosis (Annexin $\mathrm{V}+\mathrm{ve} / \mathrm{PI}+\mathrm{ve}$ ) as determined from the corresponding dot plots are represented. (b) Effect of $\mathrm{H}_{2} \mathrm{O}_{2}$ on viability of the patient's family members. Lymphoblastoid cells from control (C2ABR) patient (ATL2ABR) and the members of the family were either untreated or treated with $0.5 \mathrm{mM} \mathrm{H}_{2} \mathrm{O}_{2}$ for $24 \mathrm{~h}$ before being processed as in (a). Results were expressed as DNA damage-induced fold decrease in viable cells (calculated as the ratio of lower left quadrant before and after treatment). (c) Effect of $\mathrm{H}_{2} \mathrm{O}_{2}$ on levels of apoptosis in the patient's family members. The same data set as in (b) was used to express DNA damage-induced apoptosis as fold increase in apoptotic cells (calculated as the ratio of lower right quadrant before and after treatment). (d) Lysates from control and patient's cells treated with etoposide (E, $25 \mu \mathrm{g} / \mathrm{ml}$ ) or TRAIL (T, $4 \mu \mathrm{g} / \mathrm{ml}$ ) were resolved by SDS-PAGE and analysed for cleavage of PARP-1 by Western blotting. $\beta$-tubulin (Tubul.) was used as a loading control

Figure 4 Oxidative stress in control and patient's cells. Log-phase, non-immortalized NFF and PSF were stained for marker products of oxidative stress: 8-oxo-dG as indicator of damaged DNA (no. DR1001, Calbiochem, 1:100), 3-nitro-tyrosine as marker of damaged protein (no. 9691, Cell Signaling, 1:100) and 4HNE-Michael as marker of lipid peroxidation (no. 393207, Calbiochem, 1:100). DAPI was used as nuclear stain 

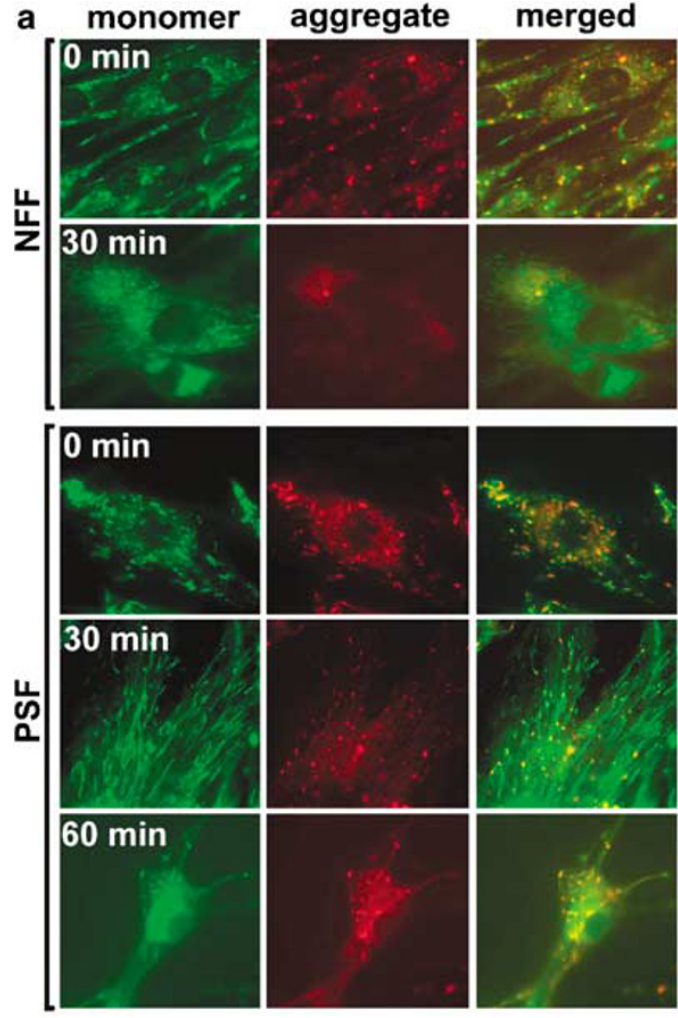

b
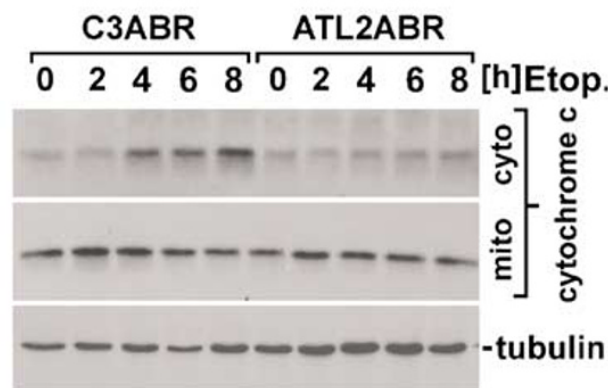

c

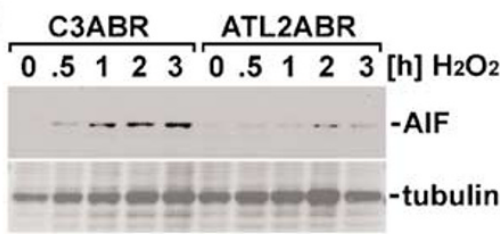

d
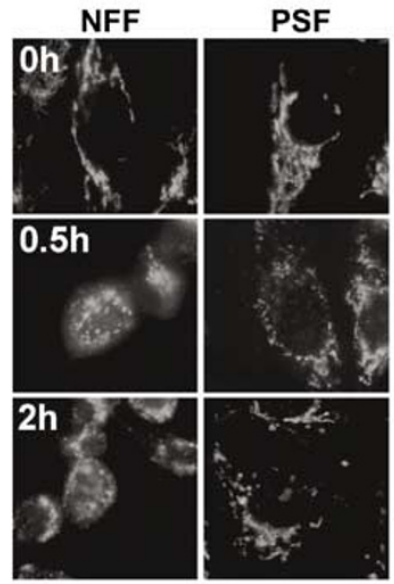

e

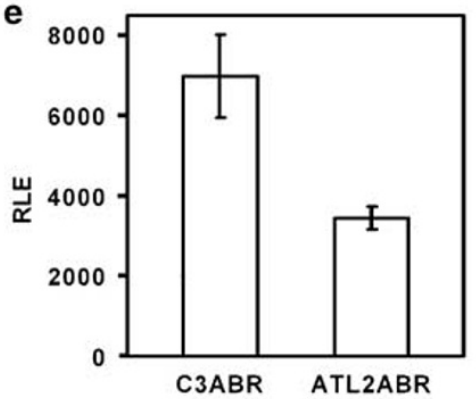

Figure 6 Mitochondrial response to genotoxic agents. (a) DNA damage-induced collapse of mitochondrial membrane potential ( $\Delta \psi \mathrm{m}$ ). NFF and PSF were loaded with $1 \mu \mathrm{g} / \mathrm{ml}$ of the fluorescence indicator dye $\mathrm{JC}-1$ for $1 \mathrm{~h}$ and subsequently treated with $1 \mathrm{mM} \mathrm{H}_{2} \mathrm{O}_{2}$ for time intervals indicated. Fluorescence images were acquired immediately without fixing the cells. The aggregated (red) form of the dye indicates intact membrane potential $(\Delta \psi \mathrm{m})$ (magnification: $\times 630)$. (b) DNA damage-induced cytochrome $c$ release. Cells were treated with $25 \mu \mathrm{g} / \mu \mathrm{l}$ etoposide for time intervals as indicated. Cytoplasmatic (cyto) and mitochondrial (mito) cytochrome $c$ was detected by Western blotting. (c) Nuclear translocation of apoptosis-inducing factor (AIF) in lymphoblastoid cells. Cells were treated with $500 \mu \mathrm{M} \mathrm{H} \mathrm{O}_{2}$ for time intervals as indicated before AIF was detected in nuclear extracts by Western blotting. Tubulin was used as loading control. (d) DNA damage-induced nuclear translocation of apoptosis inducing factor (AIF) in fibroblasts. NFF and PSF were treated with $500 \mu \mathrm{M} \mathrm{H}_{2} \mathrm{O}_{2}$ for time intervals as indicated, fixed, stained with anti-AlF antibody and anti-rabbit-AlexaFluor 488conjugate (magnification: $\times 630$ ). (e) Measurement of relative ATP levels using luciferase. ATP from control and patient lymphoblastoid cells was extracted by rapid boiling and detected using recombinant luciferase. Error bars represent the S.D. from three independent experiments (RLE: relative light emission)

radiation. ${ }^{18}$ This defect was not due to a defect in ATM, as this protein was present at normal levels, was activated by autophosphorylation and phosphorylated a number of other downstream substrates in response to DNA damage. ${ }^{18}$
No mutations were observed in p53 itself or in a number of other gene products that influence its stability. ${ }^{18}$ Posttranslational modification of p53 was normal in ATL2ABR cells in response to DNA damage but it occurred at a much

Figure 7 Oxidative stress in patient cells. (a) Comparison of levels of reactive oxygen/nitrogen species in lymphoblastoid control (C2ABR; black curve) and patient's (ATL2ABR; green curve) cells using the fluorescent dye CM- $\mathrm{H}_{2}$-DCFDA. (b) Reduction of oxidative stress by pretreatment of ATL2ABR cells with the antioxidant $N$-acety cysteine (NAC, $500 \mu \mathrm{M}$ ). Cell were untreated (blue area) or treated with NAC for 1 day (green curve) or 9 days (pink curve) before ROS/RNS levels were measured as in (a). (c) Reduction of oxidative stress by pretreatment of ATL2ABR cells with the iron chelator Desferal ( $200 \mathrm{nM}$ ). Cell were untreated (blue area) or treated with Desferal for 1 day (green curve) or 9 days (pink curve) before ROS/RNS levels were measured as in (a). (d) Effect of NAC on oxidative stress in PSF. Cells were treated with NAC (500 $\mu$ M) for 1 and 9 days or with the iron chelator Desferal $(1 \mu \mathrm{M}$ for $24 \mathrm{~h})$. Levels of oxidative stress were determined by immunostaining for the marker products nitro-tyrosine (Nitro-Y) and 4-HNA Michael. DAPI was used as DNA stain 
lower level than in control cells. In this respect, it was similar to A-T cells but the reduced response was not due to defective ATM signalling.
Although the clinical phenotype of the patient is closely related to $A O A 1$, which lacks the extraneurological features observed in A-T or A-TLD, the pattern of agent sensitivity for a

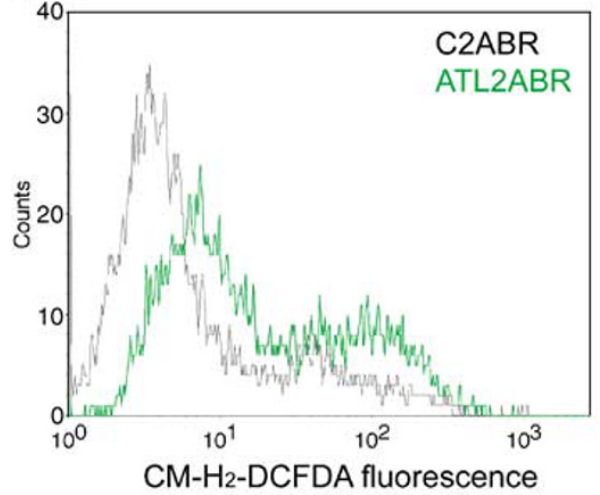

$\mathrm{CM}-\mathrm{H}_{2}$-DCFDA fluorescence

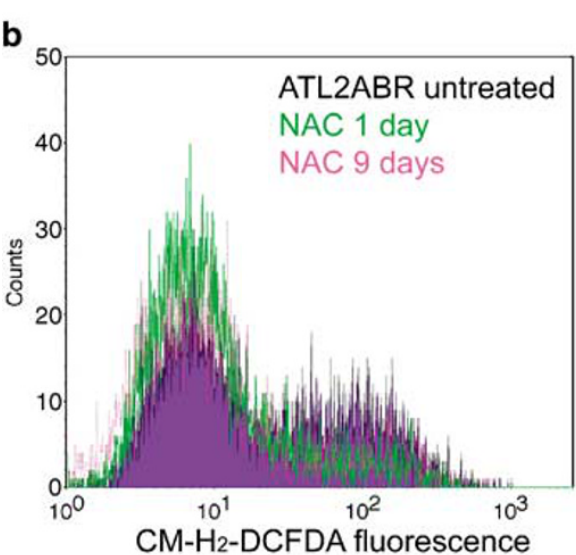

C

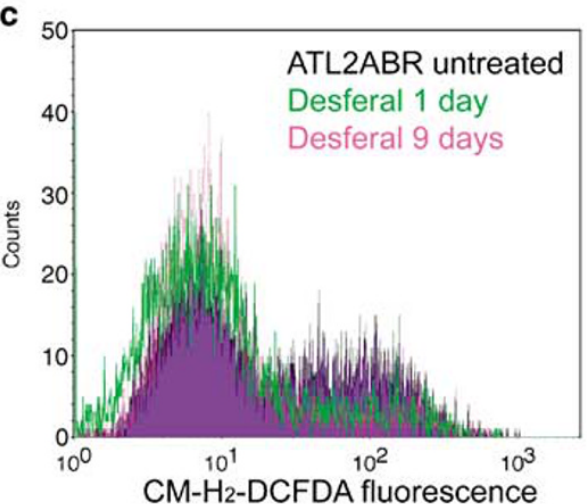

d
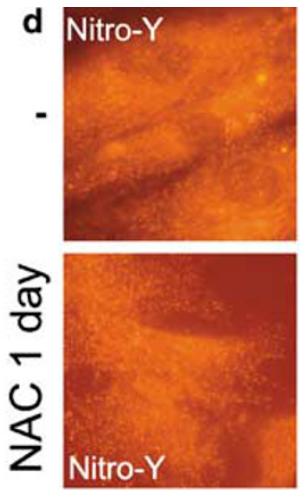

元

の

$\frac{1}{2}$
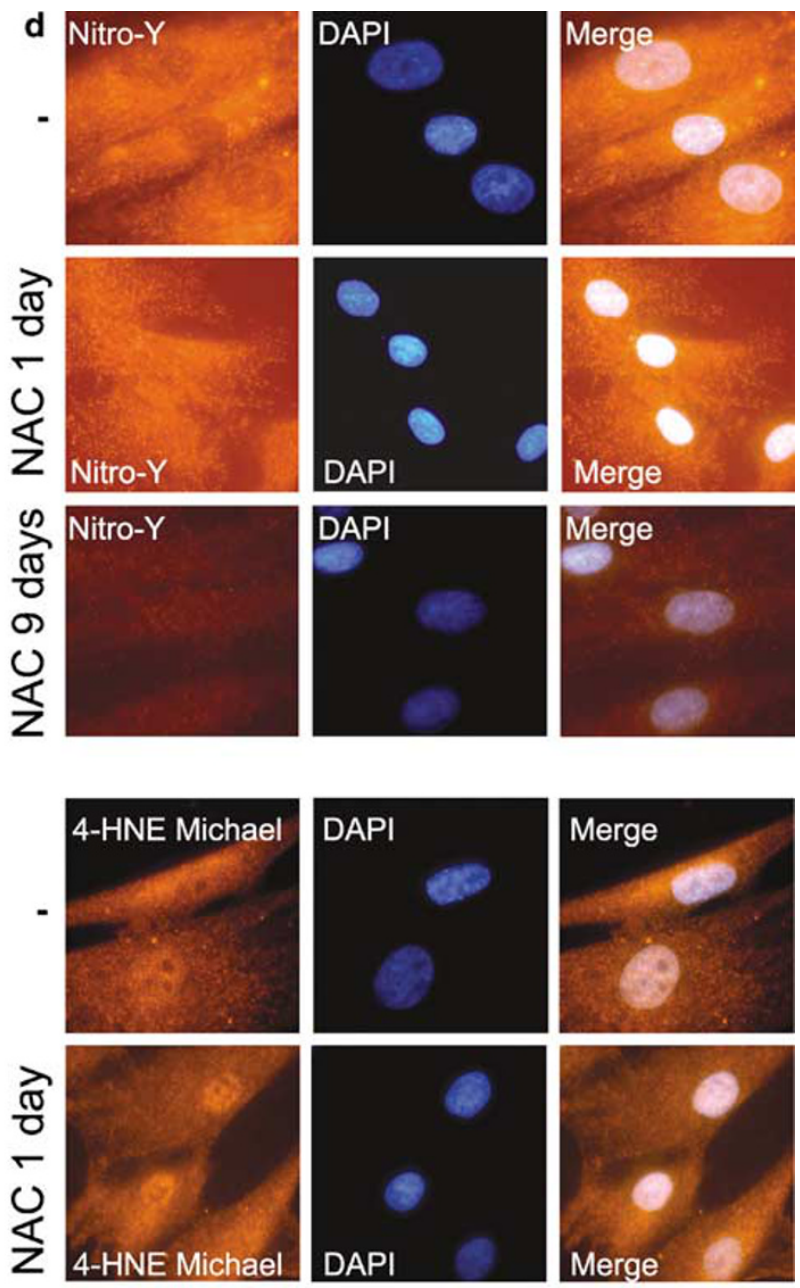

$n$
đ্
0
0
Z
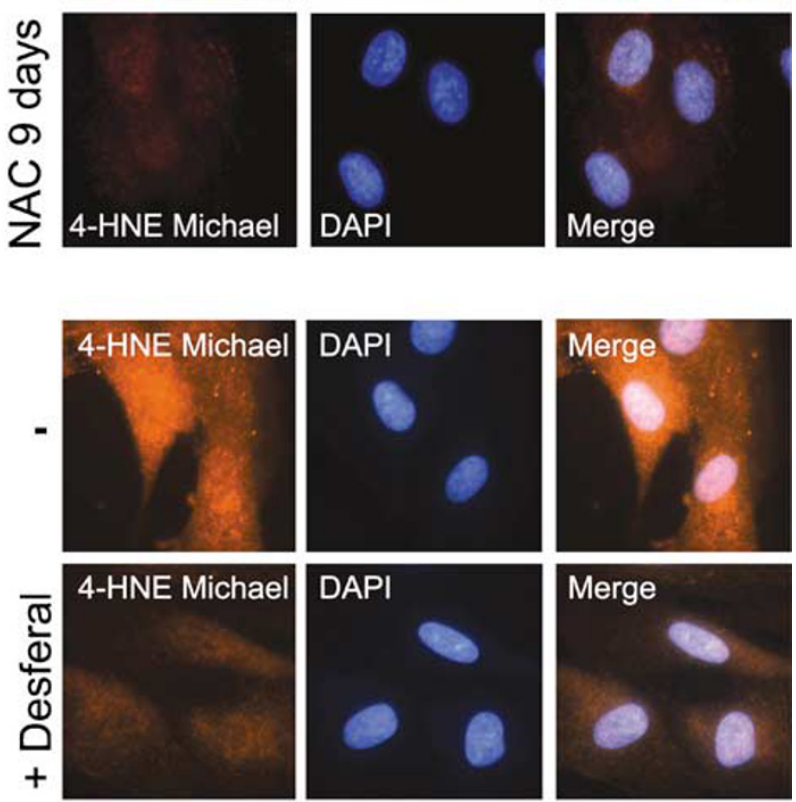

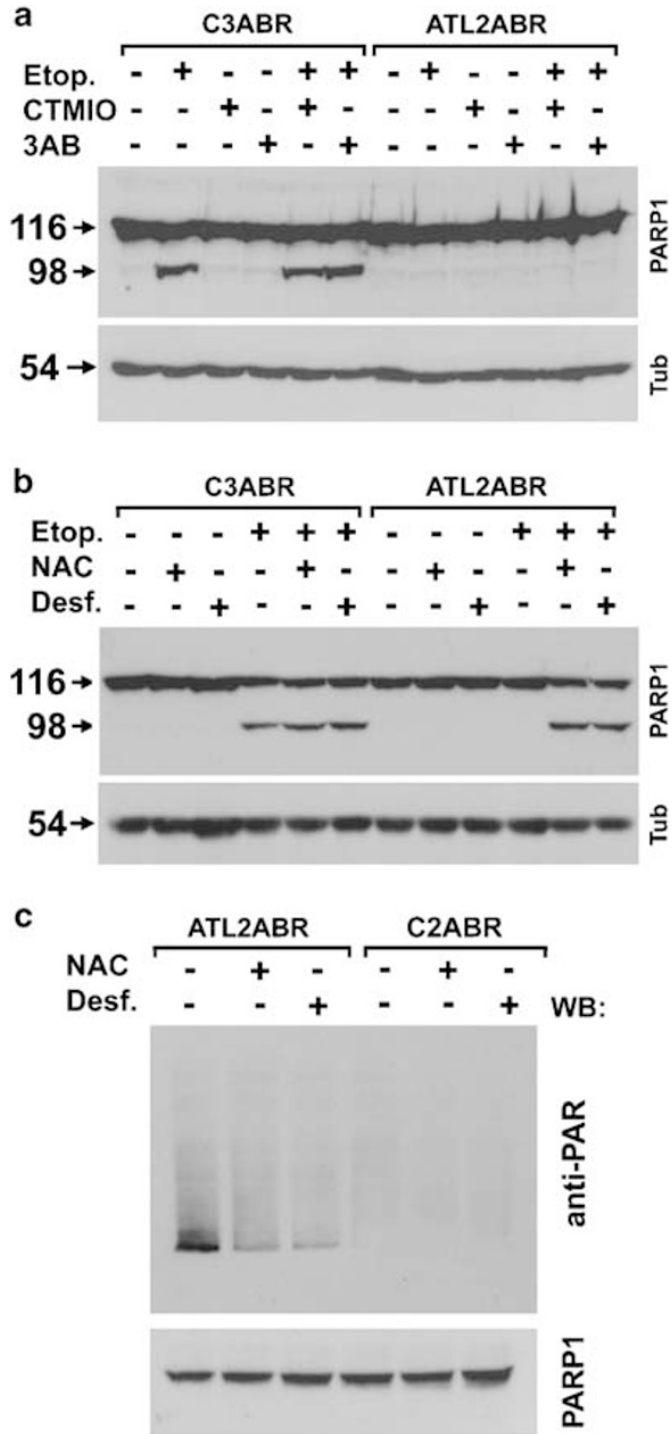

Figure 8 Restoration of apoptosis and PARP activity in patient cells by antioxidants. (a) Effect of short-term antioxidant treatment and PARP-1 inhibition on apoptosis in ATL2ABR cells. Lymphoblastoid control (C3ABR) and patient's cells (ATL2ABR) were untreated or pretreated with either the PARP-1 inhibitor 3-AB $(1 \mathrm{mM})$ or the antioxidant CTMIO $(0.1 \mathrm{mM})$ for $1 \mathrm{~h}$ before DNA damage was induced by adding etoposide $(25 \mu \mathrm{g} / \mathrm{ml})$. After a further $8 \mathrm{~h}$, cells were harvested and PARP1 cleavage detected in total cell extracts using SDS-PAGE and Western blotting. Detection of $\beta$-tubulin (Tub) was used as loading control. (b) Effect of oxidative stress on apoptosis induction by etoposide. Cells were untreated or treated for 9 days with either the antioxidant NAC $(500 \mu \mathrm{M})$ or the iron-chelator Desferal (Desf., $200 \mathrm{nM}$ ) before being treated for $8 \mathrm{~h}$ with etoposide (Etop. $25 \mu \mathrm{g} / \mathrm{ml}$ ). Apoptosis was detected by Western blotting of PARP-1 cleavage products. Detection of $\beta$-tubulin (Tub) was used as a loading control. (c) Effect of long-term treatment with antioxidants on cellular PAR levels. Control (C2ABR) and patient's cells (ATL2ABR) were untreated or pre-treated with either NAC or Desferal as described above for 9 days before cellular PAR levels were detected by Western blotting. Detection of PARP-1 was used as a loading control.

ATL2ABR cells is quite distinct from that observed in cells from other types of AOA (Table 1). ATL2ABR cells can be distinguished in their sensitivity to ionizing radiation from $A-T$ cells, which is not surprising as we have previously shown that, with the exception of p53 phosphorylation, the major
ATM signalling pathways in response to radiation are intact in these cells. ${ }^{18}$ Increased sensitivity to MMC has also been reported in Fanconi's anaemia, ${ }^{30}$ in cells with mutations in Mus81, ${ }^{31}$ Eme1, $^{32}$ Rad51 paralogs ${ }^{33}$ and Brca1-deficient cells. $^{34}$ The clinical phenotype for this patient shows no resemblance to that for $\mathrm{FA}$, which is characterized by earlyonset aplastic anaemia and cancer susceptibility, ${ }^{30}$ neither of which are apparent in this case. In addition, we found no evidence for any effect on the activity of the Mus/Eme1 endonuclease complex (results not shown). It seems more likely that the sensitivity to MMC observed here relates more to its capacity to cause oxidative damage to DNA rather than form crosslinks. ${ }^{35}$ This is in agreement with ATL2ABR sensitivity to agents such as $\mathrm{MNNG}$ and $\mathrm{H}_{2} \mathrm{O}_{2}$, which are also capable of causing oxidative damage to DNA. Furthermore, we have also shown that the patient's cells are in a constitutive state of oxidative stress as evidenced by elevated levels of ROS/RNS damage to DNA, protein and lipid.

In addition to its overlapping clinical phenotype with A-T, A-TLD and AOA1, this novel form of AOA also has a defect in the DNA damage response as evidenced by hypersensitivity to several DNA damaging agents, hyperactivation of PARP-1 and oxidative stress. For AOA1, Mosesso et al. ${ }^{28}$ described increased levels of chromosome aberrations in response to CPT treatment compared with controls and this compound also caused a significantly increased mean tail moment in AOA1 cells, as determined by the comet assay. These data provide evidence for increased numbers of breaks in AOA1 cells immediately after treatment but do not reveal a defect in DNA break repair per se. However, aprataxin, the protein defective in AOA1, physically associates with proteins involved in base excision repair and in the resolution of abortive DNA ligation intermediates, implicating it in this process. ${ }^{12-14,27}$ Unlike that in AOA1 cells, ATL2ABR cells showed normal repair levels of SSBs in response to DNA damage. Although ATL2ABR cells had no evidence of a defect in DNA single-strand repair, hyperactivation of PARP-1 in these cells might be due to an abnormality in processing of DNA breaks or due to persistent oxidative stress as evidenced by elevated levels of ROS/RNS. This hyperactivation of PARP-1 appears to be a protective response to stress, as specific PARP-1 inhibitors were toxic to these cells but caused only minimal loss of viability in control cells. Furthermore, use of antioxidants reduced elevated levels of ROS/RNS and also PARP-1 hyperactivation, suggesting a causative role for the ROS/RNS. On the other hand, although antioxidants reduced ROS/RNS within the first day of treatment, they failed to remove oxidative damage to protein and lipid but by 9 days incubation this damage had disappeared. This could be explained by a delayed and indirect effect of the antioxidants such as alteration in gene expression or a longer half-life of the damaged macromolecules.

Exposure of ATL2ABR cells to the DNA damaging agents radiation, etoposide and $\mathrm{H}_{2} \mathrm{O}_{2}$ failed to induce apoptosis. It seemed likely that the defective p53 response in these cells might explain the apoptosis resistance. ${ }^{18}$ However, although stabilization of p53 using the Mdm2 antagonist nutlin led to induction of p53 downstream effector genes, this treatment did not induce apoptosis, demonstrating that the defect occurred at a different level. ${ }^{18}$ This was further supported by 
Table 1 Specific sensitivity profile of several forms of AOA against DNA damaging agents

\begin{tabular}{lllll}
\hline Sensitivity to & A-T & A-TLD & AOA1 & ATL2ABR \\
\hline lonizing radiation & High & Intermediate & Normal & Intermediate \\
Mitomycin C & Intermediate & ND & High & High \\
$\mathrm{H}_{2} \mathrm{O}_{2}$ & Normal & ND & High & High \\
Camptothecin & Normal & ND & High & Normal \\
Etoposide & High & ND & Normal High \\
MMS & Normal & ND & High & Normal \\
MNNG & Intermediate & ND & ND & High \\
& & & &
\end{tabular}

the failure to induce apoptosis by the non-DNA damaging agent cycloheximide. The results described here extend these observations to other inducers of apoptosis, etoposide (genotoxic) and TRAIL (non-genotoxic). TRAIL induces ubiquitous pathways of cell death in which caspase activation is mediated either directly or via the release of apoptogenic factors from mitochondria. However, the precise components of the mitochondrial signalling pathway involved have not been well defined. The picture that emerges is that ATL2ABR cells are sensitive to killing by a variety of different agents but the mode of cell killing is not through apoptosis. Based on these observations, our prediction was that the mitochondria from the patient's cells would be refractory to the changes that occur during apoptosis. In agreement with this, in response to DNA damage, we failed to observe changes in mitochondrial membrane potential and there were defects in translocation of AIF from the mitochondria to the nucleus and in release of cytochrome $c$ from the mitochondria to the cytoplasm. We also observed depleted levels of ATP in these cells, which might be explained by decreased production or enhanced utilization. There is good evidence that oxidative stress causes mitochondrial dysfunction and lowered levels of ATP. ${ }^{36,37}$ Thus, the increased levels of ROS/RNS observed in ATL2ABR cells might be responsible for the depleted levels of ATP observed here. Alternatively, the hyperactivation of PARP-1 in ATL2ABR cells, which appears to be due to increased levels of ROS/RNS, would be expected to consume both NAD and ATP resulting in reduced amounts of both.

We have previously shown that ATL2ABR cells are defective in the p53 response to DNA damage but this did not account for the failure to see apoptosis, as nutlin stabilized p53 did not cause apoptosis on its own ${ }^{18}$ or when accompanied by DNA damage. ${ }^{38}$ Furthermore, under these conditions, we were able to demonstrate the presence of equal amounts of p53 associated with mitochondria in control and ATL2ABR cells (results not shown). Thus, the defect in mitochondrial response in the patient's cells is not due to a failure of p53 to signal to this organelle, a process that has been described previously to account for p53-mediated cell death, ${ }^{39}$ but rather by some other defective signalling pathway or an inherent physiological defect, which was not detected by ultra-structural studies. The capacity of the iron chelator Desferal to reduce oxidative stress and permit induction of apoptosis by etoposide in ATL2ABR cells suggests that the resistance to apoptosis, normally observed in these cells, is mediated by reactive oxygen species. We have provided evidence for this by showing that ROS/RNS are elevated in ATL2ABR cells and both NAC and Desferal reduce these species. The data obtained here agree with previous results by Lee and Shakter ${ }^{22}$ who showed that, in the presence of oxidative stress, human B-lymphoma cells are unable to undergo Etoposide-induced apoptosis. As antioxidants reduce PAR levels and as inhibition of PARP-1 in these cells did not restore apoptosis in response to DNA damage, it suggests that another characteristic of these cells, PARP-1 hyperactivation, is on a separate pathway from the oxidative stress-induced inhibition of apoptosis. It seems likely that oxidative damage to macromolecules in ATL2ABR cells is responsible for the apoptosis resistance, as elimination of ROS does not permit apoptosis but under conditions where oxidative damage is removed by antioxidants, the capacity for apoptosis is restored.

Although the form of AOA described here overlaps in its cellular phenotype with other AOAs, it possesses a unique combination of features that distinguishes it from all of the others. It has a different pattern of agent hypersensitivity (Table 1), evidence for the presence of oxidative damage to different macromolecules, hyperactivation of PARP-1, defective stabilization of $\mathrm{p} 53$ and resistance to apoptosis. These characteristics would be expected to give rise to genome instability, cancer predisposition and neurodegeneration. Failure to observe an association between this defect and cancer predisposition is similar to that observed in AOA1, where a defect in DNA SSB repair is only adversely manifested in neurons. ${ }^{9}$ The clinical phenotype of this patient provides clear evidence for the presence of a cerebellar defect, similar to that observed in other AOA syndromes that are characterized by reduced capacity to deal with damage in DNA. ${ }^{38}$ This failure to efficiently respond to various forms of DNA damage may be responsible for or contribute to the neurodegeneration that is common to all these syndromes. This could be due to a defect in a protein involved in DNAdamage recognition and/or repair, inappropriate cell death or as an indirect consequence of one of the abnormalities described here, such as PARP-1 hyperactivation, which might impact on DNA repair. In the context of the nervous system, severe stress in response to acute neuronal injury causes overactivation of PARP-1. The resulting upregulation of PAR synthesis appears to be responsible for widespread neuronal cell death ${ }^{21}$ indicating that this hyperactivation is a candidate for the neurodegeneration observed in the patient described here. However, in the present case, inhibition of PARP-1 activity enhanced cell killing, suggesting that hyperactivation of PARP-1 per se was not the major factor responsible for cell death. Identification of the gene responsible for this form of AOA will provide greater insight into its role in protection against neurodegeneration.

\section{Materials and Methods}

Cell lines and culture conditions. LCLs from control (C2ABR, C3ABR, C4ABR, C5ABR), A-T (AT1ABR, AT5ABR), AOA1 (L990, L991, L938), AOA2 (SETX-2RM), Friedreich Ataxia (FRDA1) and patient (ATL2ABR) as well as NFF and PSF were cultured in RPMI 1640 medium (GIBCO BRL, Div of Invitrogen, Gaithersburg, USA) containing $10 \%$ foetal calf serum (FCS) and maintained in a humidified incubator at $37^{\circ} \mathrm{C} / 5 \% \mathrm{CO}_{2}$. Cells were exposed to a number of different DNA damaging agents including CPT, etoposide, MMC, MMS, MNNG, hydrogen peroxide $\left(\mathrm{H}_{2} \mathrm{O}_{2}\right)$ and ionizing radiation. All irradiations were performed at room temperature using a ${ }^{137} \mathrm{Cs}$ source (Gammacell 40 Exactor, MDS Nordion, dose rate $1.1 \mathrm{~Gy} / \mathrm{min})$. Cells were incubated with the antioxidants CTMIO $(100 \mu \mathrm{M}), \mathrm{N}$-acetyl 
cysteine $(500 \mu \mathrm{M})$ and the iron chelator Desferal (200 nM; Ciba-Geigy, Pendle Hill, Australia) for time periods as indicated. For long-term incubation, culture media containing antioxidants was replaced every 2 days. All chemicals, if not stated otherwise, were obtained from Sigma (Castle Hill, New South Wales, Australia).

Cytotoxicity studies. For determining cytotoxicity of DNA damaging agents as well as the PARP-1 inhibitors PJ-34 and AG-14361, cells were suspended in RPMl 1640 medium at $2 \times 10^{5} / \mathrm{ml}$ before exposure to agents. Cells were incubated until untreated controls reached $2 \times 10^{6} / \mathrm{ml}$. Cell viability (triplicate wells for each drug concentration) was determined by adding $0.1 \mathrm{ml}$ of $0.4 \%$ trypan blue to a $0.5 \mathrm{ml}$ cell suspension. The numbers of viable cells were counted, and viabilities were expressed as the number of cells in drug-treated wells relative to cells in control wells (\% of control). Measurement of cell survival in response to genotoxic agents was performed as described above. Incubation times with genotoxic agents were as follows: CPT: $3 \mathrm{~h}$; Etoposide: $1 \mathrm{~h} ; \mathrm{H}_{2} \mathrm{O}_{2}$ : $0.5 \mathrm{~h}$; MMS: $1 \mathrm{~h}$; MNNG: $1 \mathrm{~h}$; MMC: $1 \mathrm{~h}$. Subsequently, cells were washed and resuspended in normal growth medium. After 2 days, viability was determined as described above. For determining chromosome aberrations, cells were incubated with MMC or irradiated with $1 \mathrm{~Gy} \gamma$-radiation under aerobic conditions. Colcemid (final concentration $0.1 \mu \mathrm{g} / \mathrm{ml}$ ) was added immediately after irradiation, $2 \mathrm{~h}$ before harvesting. The cells were treated for $15 \mathrm{~min}$ in $0.075 \mathrm{M}$ $\mathrm{KCl}$, fixed in methanol \pm glacial acetic acid $(3: 1)$ and the fixed cells were spread on glass slides, air-dried and stained with Giemsa. Fifty metaphases were analysed for each sample.

SSB repair assays. To induce SSB, cells were exposed to $\mathrm{H}_{2} \mathrm{O}_{2}(20 \mu \mathrm{M})$ in RPMI 1640 medium without supplements for $15 \mathrm{~min}$ at $37^{\circ} \mathrm{C}$. To remove $\mathrm{H}_{2} \mathrm{O}_{2}$, catalase $(880 \mathrm{U} / \mathrm{ml})$ was added. Cells were collected by centrifugation $(1500 \mathrm{U} / \mathrm{min}$ for $5 \mathrm{~min}$ ) and washed with PBSCMF (140 $\mathrm{mM} \mathrm{NaCl}, 3 \mathrm{mM} \mathrm{KCl}, 8 \mathrm{mM} \mathrm{Na}_{2} \mathrm{HPO}_{4}$, $1 \mathrm{mM} \mathrm{KH}{ }_{2} \mathrm{PO}_{4}$ ). The numbers of SSB were determined by alkaline elution assay either directly after damage induction or following repair incubations in full medium at $37^{\circ} \mathrm{C}$ for the indicated times. The numbers of SSB in untreated control cells were subtracted in all cases.

Western blotting. For western blotting antibodies against the following proteins were used: Actin (AC-40, Sigma, 1:1000), AIF (no. 4642, Cell Signaling Technology, Danvers, USA, $1: 1000)$; cytochrome $c(7 \mathrm{H} 8.2 \mathrm{C} 12$, BD Pharmingen, San Jose, USA, $1: 1000)$, PAR (1:500), PARP-1 (MCA1522, Serotec, Oxford, UK $1: 1000), \beta$-tubulin $(2-28-33$, Sigma, $1: 2000)$. For preparation of cell extracts, cells

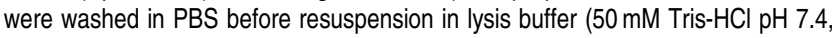
$150 \mathrm{mM} \mathrm{NaCl}, 1 \mathrm{mM}$ EDTA, $1 \% \mathrm{NP}-40$, supplemented with protease and phosphatase inhibitors and Benzonase (Novagen, San Diego, USA)) for $1 \mathrm{~h}$ at $4{ }^{\circ} \mathrm{C}$. Insoluble components were removed by centrifugation $(16000 \mathrm{~g}$ for $10 \mathrm{~min})$. Protein $(10-50 \mu \mathrm{g})$ was separated by SDS-PAGE, proteins transferred to nitrocellulose membrane and immunoblotting was performed using the appropriate antibody described above.

PARG zymogram gels. Cells were harvested and washed in PBS containing complete protease inhibitor cocktail (Roche Molecular Biochemicals, Melbourne, Australia) and suspended in sample buffer $(100 \mathrm{mM}$ Tris-HCl pH 6.8, 4\% SDS, $20 \%$ glycerol, $10 \% \beta$-mercaptoethanol, $0.2 \%$ bromophenol blue) containing protease inhibitor cocktail before sonication. Samples were neither heated nor frozen before loading. Zymogram gels were immediately performed as described ${ }^{20} u$ sing $\left[{ }^{32} \mathrm{P}\right]$ labelled automodified PARP-1 as a source of poly(ADP-ribose).

PARG activity assays. PARG activity was measured as described. ${ }^{40}$ Briefly, the reaction mixture used for the assay contained $50 \mathrm{mM}$ potassium phosphate $\mathrm{pH}$ $7.5,50 \mathrm{mM} \mathrm{KCl}, 100 \mu \mathrm{g} / \mathrm{ml}$ bovine serum albumin, $10 \mathrm{mM} \beta$-mercaptoethanol, $0.1 \mathrm{mM}$ PMSF, $10 \mu \mathrm{M}\left[{ }^{32} \mathrm{P}\right]$-labelled poly(ADP-ribose). The reaction was started by the addition of the cell extracts and stopped after $10 \mathrm{~min}$ by the addition of SDS at a final concentration of $0.1 \%$. An aliquot of each reaction was applied onto a polyethyleneimine-cellulose TLC plate. The plate was first developed at room temperature in methanol, dried, and then developed in $0.3 \mathrm{M} \mathrm{LiCl}, 0.9 \mathrm{~N}$ acetic acid. The TLC plate was electronically autoradiographed on Instant Image Analyzer (Packard Instrument Company, Illinois, USA) to determine the amount of radioactivity in each spot. The amounts of radioactivity found in the ADP-ribose spot and the origin were used to calculate PARG-specific activity. Protein concentration was determined by the Bradford assay (BioRad, Hercules, USA). One unit of PARG is defined as the amount of enzyme required to release $1 \mathrm{nmol}$ of ADP-ribose per min at $37^{\circ} \mathrm{C}$ under assay conditions.
Immunostaining of cells. NFF and PSF were grown on glass coverslips for $48 \mathrm{~h}$, washed with PBS and fixed in $2 \%$ paraformaladehyde/PBS for $10 \mathrm{~min}$ and processed for immunofluorescence as previously described ${ }^{22}$ using antibodies against AIF (no. 4642, Cell Signaling, 1:100); nitro-tyrosine (no. 9691, Cell Signaling, 1:100); 4-HNE-Michael (no. 393207, Calbiochem, San Diego, USA, $1: 100)$ on paraformaldehyde fixed cells. Images were captured using a digital camera (Carl Zeiss, North Ryde, Australia) attached to a fluorescent microscope Axioskop2 mot plus (Carl Zeiss). For the detection of $8-0 \times 0-d G$ by immunofluorescence cells were fixed with $100 \%$ pre-chilled methanol for $5 \mathrm{~min}$ and immersed in $100 \%$ pre-chilled acetone for $5 \mathrm{~min}$. Coverslips were subsequently air-dried, treated with $0.05 \mathrm{~N} \mathrm{HCl}$ for 5 min on ice and washed three times with PBS. RNA was digested by incubating the coverslips in $100 \mu \mathrm{g} / \mathrm{ml}$ RNase in $150 \mathrm{mM} \mathrm{NaCl}$ with $15 \mathrm{mM}$ sodium citrate for $1 \mathrm{~h}$ at $37^{\circ} \mathrm{C}$. After RNA digestion, coverslips were sequentially washed in PBS, 35\% ethanol, $50 \%$ ethanol and $75 \%$ ethanol for $2 \mathrm{~min}$ each. DNA was denatured by incubating the coverslips with $0.15 \mathrm{~N} \mathrm{NaOH}$ in $70 \%$ ethanol for $4 \mathrm{~min}$. A series of washes were performed starting with $70 \%$ ethanol containing $4 \% \mathrm{v} / \mathrm{v}$ formaldehyde, then $50 \%$ ethanol, $35 \%$ ethanol and finally PBS for $2 \mathrm{~min}$ each. Proteins were digested with $5 \mu \mathrm{g} / \mathrm{ml}$ proteinase $\mathrm{K}$ in TE pH 7.5 for $10 \mathrm{~min}$ at $37^{\circ} \mathrm{C}$. After several PBS washes, coverslips were incubated with anti-8 oxo-dG antibody (no. 4355-MC-100, Trevigen, $1: 250)$ in PBT20 $(1 \times \mathrm{PBS} / 1 \%$ $\mathrm{BSA} / 0.1 \%$ Tween 20 ) for $1 \mathrm{~h}$ at room temperature. Following several washes with $0.1 \times$ PBS, 8-oxoG was detected using an AlexaFluor488 secondary antibody (Invitrogen, Carlsbad, CA, USA, 1/500 in PBT20). Nuclei were counterstained with DAPI and slides were mounted for immunofluorescence. Images were captured as described above.

FACS analysis of apoptosis. Cells $\left(5 \times 10^{4}\right)$ were pelleted $(500 \times \mathrm{g}$ for $5 \mathrm{~min}$ ) in 96-well $\mathrm{V}$ bottom plates and resuspended in $100 \mu \mathrm{l}$ Annexin $\mathrm{V}$ buffer (10 mM HEPES- $\mathrm{NaOH}$ pH7.4, $150 \mathrm{mM} \mathrm{NaCl}, 5 \mathrm{mM} \mathrm{KCl}, 1 \mathrm{mM} \mathrm{MgCl} 2,1.8 \mathrm{mM}$ $\mathrm{CaCl}_{2}, 0.5 \mathrm{mg} / \mathrm{ml}$ Annexin V-FITC, $0.5 \mu \mathrm{g} / \mathrm{ml} \mathrm{PI}$ ). Annexin V binding and PI uptake was determined by flow cytometry using a FACSCalibur (Becton Dickinson, San Jose, USA). Cells were detected by size and granularity using FSC/SSC and cell debris was gated out. Annexin V-FITC and PI were detected in FL-1 and FL-2, respectively.

Mitochondrial cytochrome $c$ release. For measuring DNAdamageinduced cytochrome $c$ release, cells were collected after induction of DNA damage at different time points and the cell membrane permeabilized in $50 \mu \mathrm{l}$ (PBS, $100 \mathrm{mM} \mathrm{KCl}, 50 \mu \mathrm{g} / \mathrm{ml}$ digitonin) for $5 \mathrm{~min}$. After spinning (10 min, $13000 \mathrm{~g}, 4^{\circ} \mathrm{C}$ ) the supernatant was collected and termed cytoplasmic fraction. The pellet was lysed in $50 \mu$ regular lysis buffer (see Western blotting) to obtain the residual mitochondrial cytochrome $c$. Proteins from both fractions were resolved by $15 \%$ SDS-PAGE under standard conditions on the same gel and detected using monoclonal anticytochrome $c$ antibody (7H8.2C12, BD Pharmingen, $1: 1000)$ and HRP-conjugated anti-mouse antibody (Selenius, Billarica, USA, 1:5000). Owing to low apoptosis levels cytoplasmic and residual protein fractions were loaded at a ratio of $5: 1$.

Detection of mitochondrial membrane potential. Mitochondrial membrane potential was detected using the potential-sensitive fluorescent dye JC-1 (Invitrogen) according to the manufacturers recommendations. Briefly, cells were loaded with the dye $(1 \mu \mathrm{g} / \mathrm{ml}$ in growth medium) for $30 \mathrm{~min}$ before being exposed to $\mathrm{H}_{2} \mathrm{O}_{2}$. After different times, unfixed cells were examined for the monomeric (green fluorescence) and aggregated (red fluorescence; indicating intact membrane potential) form of JC-1 using epifluorescence microscopy (Axioskop 2Mot plus and Plan Apochromat $63 \times / 1.4$ Oil, Zeiss, North Ryde, Australia).

Relative measurement of cellular ATP levels. ATP was extracted from cells in the exponential phase of growth using the Tris/EDTA boiling method and measured by the luciferin/luciferase method. Briefly, $10^{6}$ cells were pelleted (volume approximately $5 \mu \mathrm{l}$ ) and resuspended in $200 \mu \mathrm{l}$ boiling extraction buffer $(100 \mathrm{mM}$ Tris pH 7.8, $2 \mathrm{mM}$ EDTA). After further boiling for $90 \mathrm{~s}$, the samples are chilled on ice and centrifuged $\left(16000 \times \mathrm{g} ; 5 \mathrm{~min} ; 4^{\circ} \mathrm{C}\right)$ to remove insoluble material and snap frozen on dry ice. Reaction was started by adding $90 \mu \mathrm{l}$ of cell extract to $10 \mu \mathrm{l}$ of reaction buffer $(0.4 \mathrm{mM}$ luciferin $(12.3 \mathrm{mg} / \mathrm{ml}), 1.25 \mathrm{mg} / \mathrm{ml}$ luciferase, $25 \mathrm{mM}$ Tricine buffer (pH 7.8), $5 \mathrm{mM} \mathrm{MgSO}_{4}, 100 \mathrm{mM}$ EDTA and $1 \mathrm{mM} \mathrm{DTT}$ ). Luminescence was analysed after a $2 \mathrm{~s}$ delay with a $10 \mathrm{~s}$ integration on a TD-20/20 luminometer (Turner Designs) (RLE: relative light emission). 
Measurement of reactive oxygen/nitrogen species using flow cytometry. For flow cytometry, $10^{6}$ cells were harvested and briefly washed twice in Dulbecco's phosphate-buffered saline (D-PBS, Invitrogen) before resuspension for $15 \mathrm{~min}$ in $1 \mathrm{ml} \mathrm{D-PBS}$ containing $1 \mu \mathrm{M} \mathrm{5}$-(and 6-) chloromethyl$2^{\prime}, 7^{\prime}$-dichlorodihydrofluorescein diacetate, acetyl ester (CM- $\mathrm{H}_{2}$-DCFDA) (Molecular Probes, Eugene, OR, USA). After washing twice with PBS, cells were analysed immediately by flow cytometry (FACS Scan, Becton-Dickinson) according to the manufacturer's recommendations. Cells were detected by size and granularity using $\mathrm{FSC} / \mathrm{SSC}$ and cell debris was gated out before 5000 events were collected for analysis.

Acknowledgements. We acknowledge the Australian National Health and Medical Research Council for funding. We thank Steve Bottle for the CTMIO antioxidant, which was produced in part with the support of the Australian Research Council under the ARC Centres of Excellence program. We thank Dr. Z Hostomsky (Pfizer Global Research and Development Inc., La Jolla, USA) for the PARP-1 inhibitor AG-14361. We thank Aine Farrell for assistance with cell culture.

1. Aicardi J, Barbosa C, Andermann E, Andermann F, Morco R, Ghanem $Q$ et al. Ataxiaocular motor apraxia: a syndrome mimicking ataxia-telangiectasia. Ann Neurol 1988; 24 497-502.

2. Boder E. Ataxia-telangiectasia: an overview. Kroc Found Ser 1985; 19: 1-63.

3. Savitsky K, Bar-Shira A, Gilad S, Rotman G, Ziv Y, Vanagaite L et al. A single ataxia telangiectasia gene with a product similar to PI-3 kinase. Science 1995; 268: 1749-1753.

4. Boder E, Sedgwick RP In: Hereditary Neuropathies and Spinocerebellar Atrophies Vinkin PJ, Bruyn W, Klawans HL (eds) ( New York: Liss AR ) 1991 pp. 347-423.

5. Taylor AMR, Groom A, Byrd PJ. Ataxia-telangiectasia-like disorder (ATLD)- its clinical presentation and molecular basis. DNA Repair 2004; 3: 1219-1225.

6. Carney JP, Maser RS, Olivares H, Davis EM, Le Beau M, Yates JR et al. The hMre11/ hRad50 protein complex and Nijmegen breakage syndrome: linkage of double-strand break repair to the cellular DNA damage response. Cell 1998; 93: 477-486.

7. Stewart GS, Maser RS, Stankovic T, Bressan DA, Kaplan MI, Jaspers NG et al. The DNA double-strand break repair gene hMRE11 is mutated in individuals with an ataxiatelangiectasia-like disorder. Cell 1999; 99: 577-587.

8. Lavin MF. The Mre11 complex and ATM: a two-way functional interaction in recognizing and signaling DNA double strand breaks. DNA Repair 2004; 3: 1515-1520.

9. Le Ber I, Moreira MC, Rivaud-Pechoux S, Chamayou C, Ochsner F, Kuntzer T et al. Cerebellar ataxia with oculomotor apraxia type 1: clinical and genetic studies. Brain 2003; 126 (Part 12): 2761-2772.

10. Date H, Onodera O, Tanaka H, Iwabuchi K, Uekawa K, Igarashi S et al. Early-onset ataxia with ocular motor apraxia and hypoalbuminemia is caused by mutations in a new HIT superfamily gene. Nat Genet 2001; 29: 184-188.

11. Moreira MC, Barbot C, Tachi N, Kozuka N, Uchida E, Gibson T et al. The gene mutated in ataxia-ocular apraxia 1 encodes the new HIT/Zn-finger protein aprataxin. Nat Genet 2001 29: $189-193$.

12. Gueven N, Becherel OJ, Kijas AW, Chen P, Howe O, Rudolph JH et al. Aprataxin, a nove protein that protects against genotoxic stress. Hum Mol Genet 2004; 13: 1081-1093.

13. Kijas AW, Harris JL, Harris JM, Lavin MF. Aprataxin forms a discrete branch in the HIT (Histidine Triad) superfamily of proteins with both DNA/RNA binding and nucleotide hydrolase activities. J Biol Chem 2006; 281: 13939-13948.

14. Ahel I, Rass U, El-Khamisy SF, Katyal S, Clements PM, McKinnon PJ et al. The neurodegenerative disease protein aprataxin resolves abortive DNA ligation intermediates. Nature 2006; 443: 713-716.

15. Le Ber I, Bouslam N, Rivaud-Pechoux S, Guimaraes J, Benomar A, Chamayou C et al. Frequency and phenotypic spectrum of ataxia with oculomotor apraxia 2: a clinical and genetic study in 18 patients. Brain 2004; 127: 759-767.

16. Moreira MC, Klur S, Watanabe M, Nemeth AH, Le Ber I, Moniz JC et al. Senataxin, the ortholog of a yeast RNA helicase, is mutant in ataxia-ocular apraxia 2. Nat Genet 2004; 36 225-227.
17. Caldecott KW. DNA single-strand breaks and neurodegeneration. DNA Repair 2004; 3 : 875-882.

18. Gueven N, Becherel OJ, Birrell G, Chen P, DelSal G, Carney JP et al. Defective p53 response and apoptosis associated with an ataxia-telangiectasia-like phenotype. Cancer Res 2006; 66: 2907-2912

19. Junod $A F$, Jornot $L$, Petersen $H$. Differential effects of hyperoxia and hydrogen peroxide on DNA damage, polyadenosine diphosphate-ribose polymerase activity, and nicotinamide adenine dinucleotide and adenosine triphosphate contents in cultured endothelial cells and fibroblasts. J Cell Physiol 1989; 140: 177-185.

20. Brochu G, Shah GM, Poirier GG. Purification of poly(ADP-ribose) glycohydrolase and detection of its isoforms by a zymogram following one- or two-dimensional electrophoresis. Anal Biochem 1994; 218: 265-272.

21. Koh DW, Dawson TM, Dawson VL. Poly(ADP-ribosyl)ation regulation of life and death in the nervous system. Cell Mol Life Sci 2005; 62: 760-768.

22. Lee YJ, Shacter E. Hydrogen peroxide inhibits activation not activity, of cellular caspase-3 in vivo. Free Radic Biol Med 2000; 29: 684-692.

23. Green DR. Apoptotic pathways: ten minutes to dead. Cell 2005; 121: 671-674.

24. Chen P, Peng C, Luff J, Spring K, Watters D, Bottle S et al. Oxidative stress is responsible for deficient survival and dendritogenesis in purkinje neurons from ataxia-telangiectasia mutated mutant mice. J Neurosci 2003; 23: 11453-11460.

25. Damiani E, Kalinska B, Canapa A, Canestrari S, Wozniak M, Olmo E et al. The effects of nitroxide radicals on oxidative DNA damage. Free Radic Biol Med 2000; 28: 1257-1265.

26. Koenig M. Rare forms of autosomal recessive neurodegenerative ataxia. Semin Pediatr Neurol 2003; 10: 183-192.

27. Luo H, Chan DW, Yang T, Rodriguez M, Chen BP, Leng M et al. A new XRCC1-containing complex and its role in cellular survival of methyl methanesulfonate treatment. Mol Cell Biol 2004; 24: 8356-8365

28. Mosesso P, Piane M, Palitti F, Pepe G, Penna S, Chessa L. The novel human gene aprataxin is directly involved in DNA single-strand-break repair. Cell Mol Life Sci 2005; 62: 485-491.

29. Ursic D, Chinchilla K, Finkel JS, Culbertson MR. Multiple protein/protein and protein/RNA interactions suggest roles for yeast DNA/RNA helicase Sen1p in transcription, transcription-coupled DNA repair and RNA processing. Nucleic Acids Res 2004; 32: 2441-2452.

30. Wang $X$, D'Andrea AD. The interplay of Fanconi anemia proteins in the DNA damage response. DNA Repair (Amsterdam) 2004; 3: 1063-1069.

31. McPherson JP, Lemmers B, Chahwan R, Pamidi A, Migon E, Matysiak-Zablocki E et al. Involvement of mammalian Mus 81 in genome integrity and tumor suppression. Science 2004; 304: 1822-1826.

32. Abraham J, Lemmers B, Hande MP, Moynahan ME, Chahwan C, Ciccia A et al. Eme1 is involved in DNA damage processing and maintenance of genomic stability in mammalian cells. EMBO J 2003; 22: 6137-6147.

33. Takata M, Sasaki MS, Tachiiri S, Fukushima T, Sonoda E, Schild D et al. Chromosome instability and defective recombinational repair in knockout mutants of the five Rad51 paralogs. Mol Cell Biol 2001; 21: 2858-2866.

34. Scully R, Chen J, Ochs RL, Keegan K, Hoekstra M, Feunteun J et al. Dynamic changes of BRCA1 subnuclear location and phosphorylation state are initiated by DNA damage. Cell 1997: 90: 425-435.

35. Krishna MC, DeGraff W, Tamura S, Gonzalez FJ, Samuni A, Russo A et al. Mechanisms of hypoxic and aerobic cytotoxicity of mitomycin $\mathrm{C}$ in Chinese hamster V79 cells. Cancer Res 1991; 51: 6622-6628

36. Zhang $X$, Wu $X Q$, Lu S, Guo YL, Ma X. Deficit of mitochondria-derived ATP during oxidative stress impairs mouse MIl oocyte spindles. Cell Res 2006; 16: 841-850.

37. Jones DP. Disruption of mitochondrial redox circuitry in oxidative stress. Chem Biol Interact 2006; 163: 38-53.

38. Gueven N, Chen P, Nakamura J, Becherel OJ, Kijas AW, Grattan-Smith $\mathrm{P}$ et al. A subgroup of spinocerebellar ataxias defective in DNA damage responses. Neuroscience 2007 (E-pub ahead of print).

39. Marchenko ND, Zaika A, Moll UM. Death signal-induced localization of p53 protein to mitochondria. A potential role in apoptotic signaling. J Biol Chem 2000; 275: 16202-16212.

40. Jonsson GG, Menard L, Jacobson EL, Poirier GG, Jacobson MK. Effect of hyperthermia on poly (adenosine diphosphate-ribose) glycohydrolase. Cancer Res 1988; 48: 4240-4243. 